\title{
Pricing in Supply Chain under Vendor Managed Inventory
}

\author{
Subramanian Nachiappan ${ }^{1}$ and Natarajan Jawahar ${ }^{2}$ \\ 1,2Department of Mechanical Engg., Thiagarajar College of Engineering Madurai \\ ${ }^{1}$ Nottingham University Business School, Jubilee Campus, Nottingham
}

\section{Introduction}

The successful implementation of supply chain management depends on many soft issues (strategic/behavioural) such as organizational resistance to change, inter-functional conflicts, joint production planning, profit sharing, team oriented performance measures, channel power shift, information sharing, real time communication, inventory and technical compatibility (Min \& Zhou 2002). Many of the above issues in SCM are conceptually addressed and lot of scope exists for improving the performance of SC with good modelling. The soft issues of supply chain models can be dealt through proper information sharing, communication and coordination between the stages of supply chain. Vendor managed inventory (VMI) is a proven concept for successful collaborative and cooperative agreements in supply chain. While research has been slowly increasing in the area of vendor managed inventory, it has received very little attention in current operations literature. This chapter focuses on the soft issues of profit sharing and pricing under vendor managed inventory systems. Two vital parameters that govern the operation of a supply chain are: sales price at buyers market, and contract price between vendor and buyer. Sales price is significant in the sense that it determines the overall profit of the supply chain, referred here as channel profit. This chapter proposes five mathematical models under VMI environment for determination of optimal sales quantity for each buyer which maximizes the channel profit and subsequently to derive the sales and contract price from the optimal sales quantity.

\section{Two-echelon supply chains}

In the present internet / E-commerce arena, the stages in SC are less and the manufacturers access the customer requirement through retailers. Dell computers have reoriented its strategy by reducing it's down-stream stages and sells through its retail outlets in a particular region (Chopra, 2003). Procter and Gamble manages, monitors and replenishes its FMCG products in Wal-Mart stores (Clark \& Croson, 1994). The success stories of these Giants have led the researchers to concentrate on two-echelon supply chain (Cachon \& Zipkin, 1999). The two-echelon can be considered sequentially between any two of these stages such as suppliers, manufacturers, distributors, wholesalers, retailers, and endcustomer. There are three types of environments addressed in two-echelon SC and they are: 
i. Single vendor-single buyer (Banerjee, 1986; Goyal, 1997; Hill, 1997; Viswanathan, 1998; Bhattacharjee \& Ramesh, 2000; Goyal \& Nebebe, 2000; Hoque \& Goyal, 2000; Dong \& $\mathrm{Xu}, 2002$; Lee \& $\mathrm{Chu}, 2005)$,

ii. Single vendor-multiple buyers (Lu 1995; Gavirneni, 2001 and Yao \& Chiou 2004) and iii. Multiple vendors - multiple buyers (Cachon, 2001; Minner 2003; Sedarage et al., 1999; Ganeshan, 1999).

The above three environments addressed by the numerous researchers were operating under independent mode with various objectives. Single vendor-single buyer is considered as an idealistic one in dealing with bottleneck cases and the remaining two cases represent the most practical situations. This chapter proposes five types of environments in twoechelon supply chain model operating under vendor managed inventory mode as given below (Nachiappan et al. 2006; Nachiappan \& Jawahar 2007; Nachiappan et al. 2007; Nachiappan et al. 2007a). The parameters involved are explained at the end of the model description.

i. $\quad$ Single Vendor Single Buyer (SV_SB)

The single vendor single buyer as shown in figure1 is known as an idealistic case.
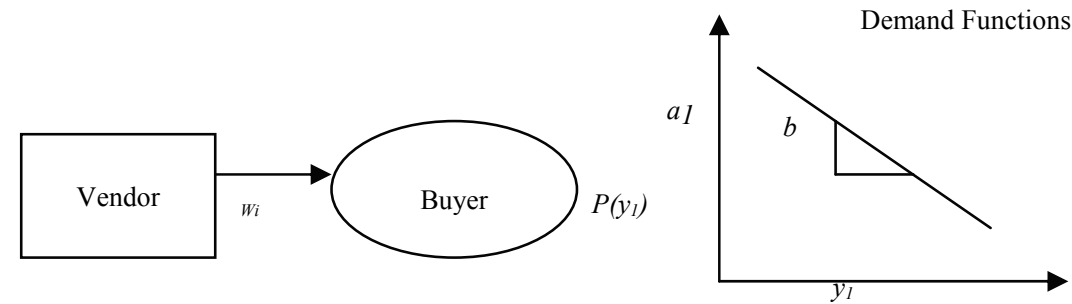

Figure 1SV_SB Model

ii. Single Vendor Multiple Buyer's (SV_MB)

Single vendor multiple buyer's case is shown in figure 2. Few examples for this case cases are: Tamilnadu Cooperative milk producer's federation limited (AAVIN) Madurai, India (Single Vendor) selling its milk products to 423 commission agents (Multiple Buyers) in and around Madurai; Bharat Petroleum Corporation, Cochin, India (Single Vendor) distributing its petroleum products to 2500 sales points (Multiple Buyers) in southern part of India.

iii. Single Vendor Multiple Buyer's with Outsourcing (SV_MBO)

When the cumulative demand of all buyers goes up more than the vendor capacity, outsourcing is the option for the vendor to satisfy buyer's demand. Nowadays outsourcing is becoming part of regular activity in both manufacturing organizations and service providers.

Globalization pushes both of them into highly competitive environment. Outsourcing occurs because a firm may find it less profitable or not feasible to produce all required capabilities in-house. Outsourcing is an acceptable strategy to meet the excess demands than the limited capacity of the vendor. Outsourcing incorporated with SV_MB model, operating under VMI mode as shown in figure 3 is referred as Single Vendor Multiple Buyers with Outsourcing (SV_MBO) 


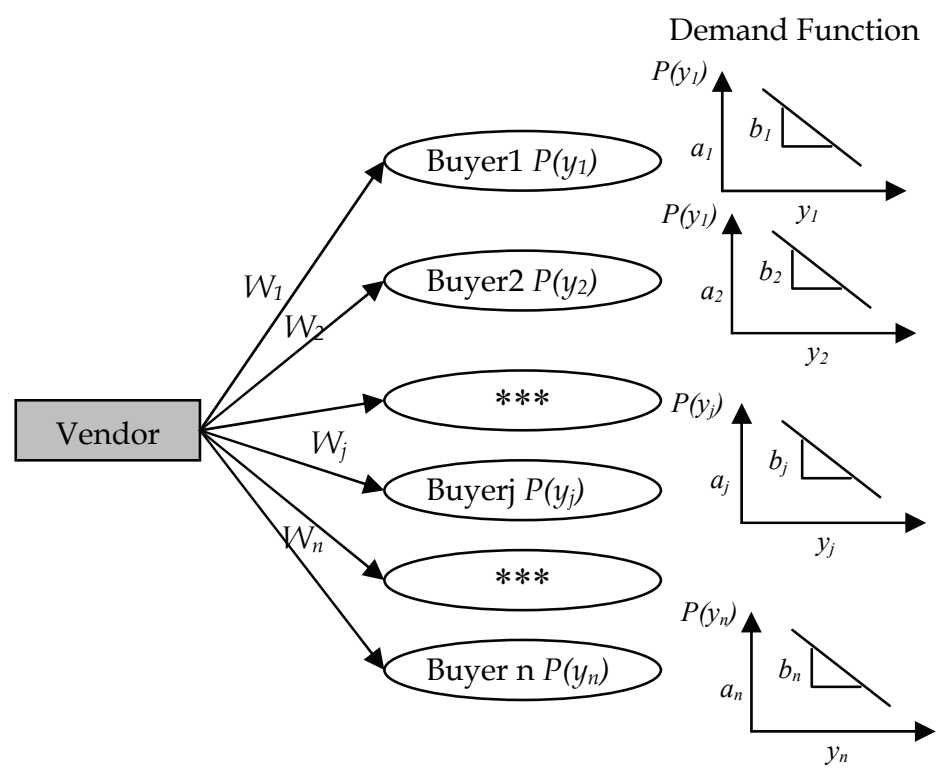

Figure 2. SV_MB model

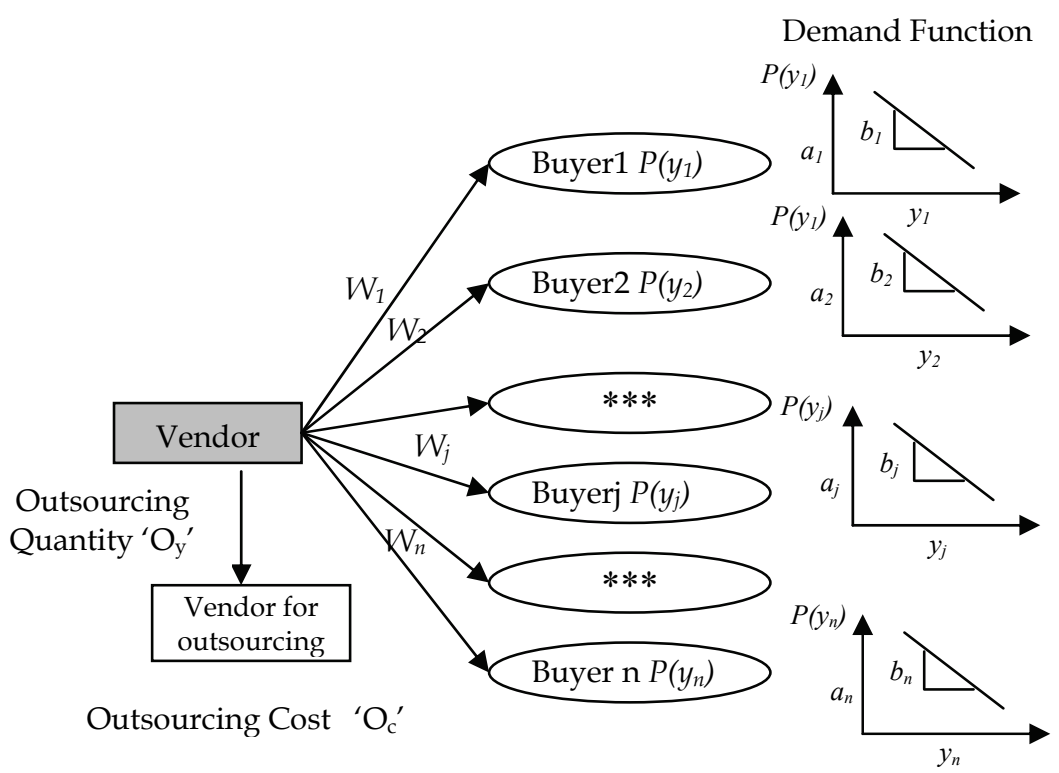

Figure 3. SV_MBO Model 
iv. Multiple Vendors Multiple Buyers (MV_MB)

Few examples of multiple vendors multiple buyers as shown in figure 4 are as follows: Gold suppliers (Multiple Vendors) are selling gold through thousands of retailer's network (Multiple Buyers) and numerous grain suppliers (Multiple Vendors) supplying grains through thousands of retailers (Multiple Buyers).

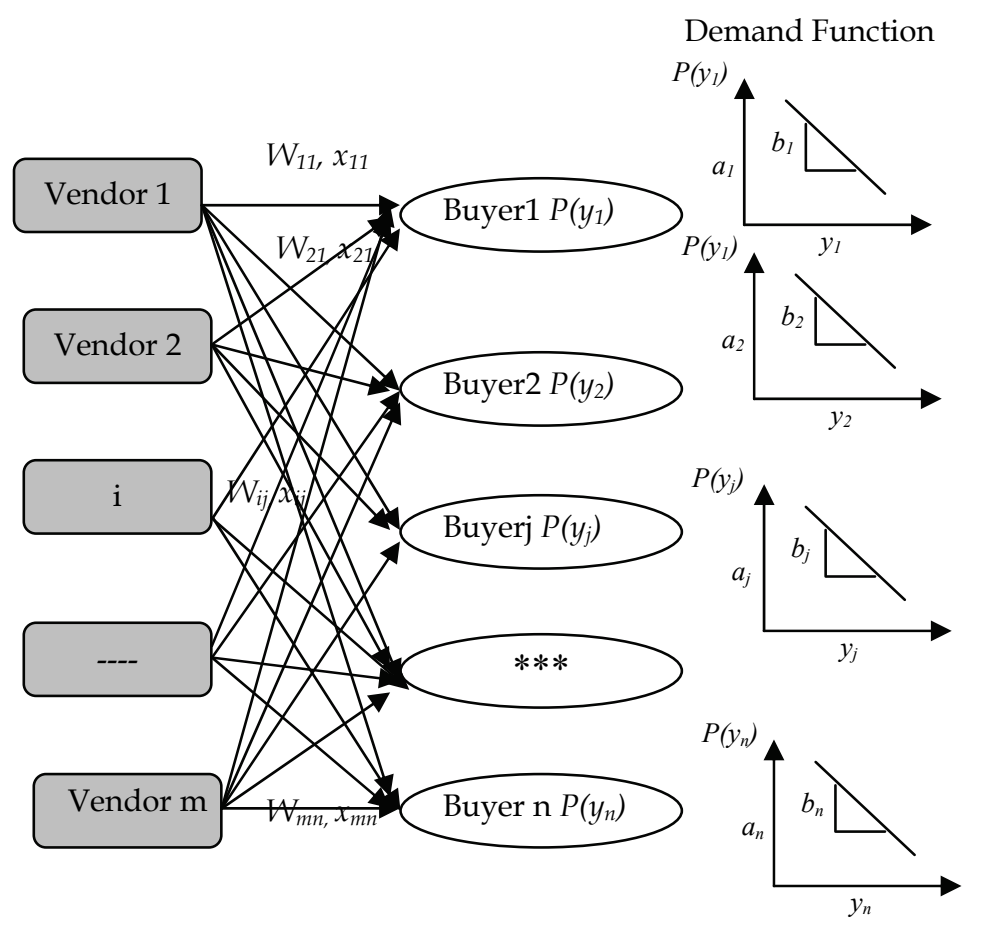

Figure 4. MV_MB model

v. Multiple Vendors Multiple Buyers with Outsourcing (MV_MBO)

Similar to SV_MBO whenever the cumulative demand of all buyers exceeds the capacity of all vendors, outsourcing is the only option for the vendors to satisfy the buyers demand. The MV_MB model with outsourcing (MV_MBO) is shown in figure 5.

\section{Model Parameters}

The demand pattern, sales quantity range at the buyers end and the importance of contract price between vendor(s) and buyer(s) are given below

Demand Pattern: The sales quantity of any product at a particular location is greatly influenced by its sales price $P\left(y_{j}\right)^{\prime}$ (Waller et. al., 2001). It depends on the factors such as necessity of the commodity (essential or occasional), purchasing power of the customers and nature of the product (perishable or storable). The general observation is that the higher sales price results low sales quantity and vice versa, provided the reputation and history of the company or brand value have no greater impact on the customers and/or there is at least one stiff customer (local or global) to control the sales price. 


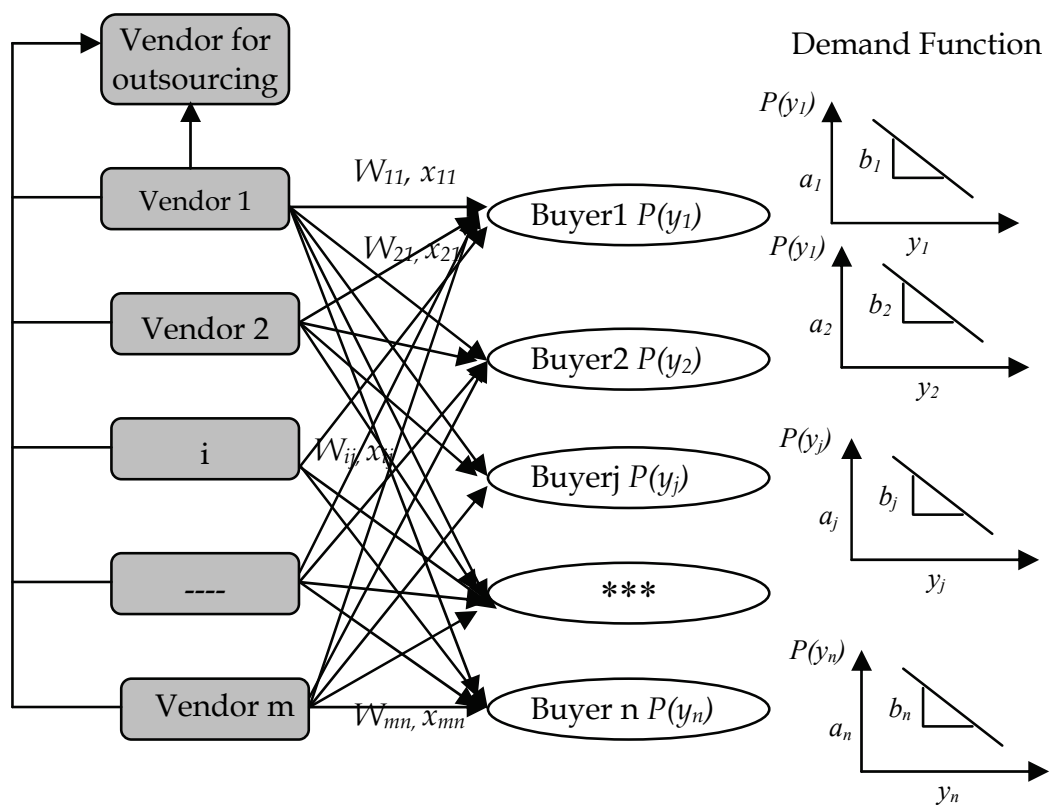

Figure 5. MV_MBO model

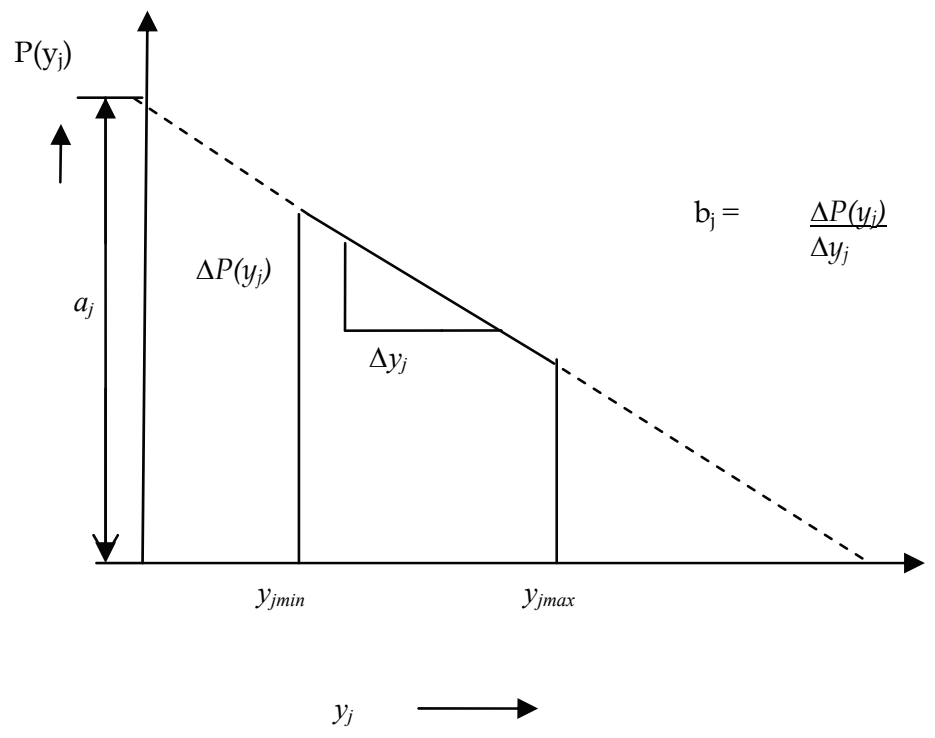

Figure 6. Relationship between sales price and sales quantity 
Taking into account the above for consideration, the relationship between ' $P\left(y_{j}\right)$ ' and ' $y_{j}$ ' may be assumed to behave linearly (Lau \& Lau, 2003) and is given as:

$$
P\left(y_{j}\right)=a_{j}-b_{j} y_{j}
$$

Where, $a_{j}$ and $b_{j}$ are the intercept of ' $P\left(y_{j}\right)$ ' axis and the slope of sales quantity /curve respectively in the sales price vs sales quantity graph shown in figure 6 . This becomes the demand function for the buyer

Sales Quantity Range: Sales quantity lies between a specific range between $y_{\text {jmin }}$ and $y_{\text {jmax }}$ and the validity of the assumption of linear demand function holds very well within this range.

Contract Price: Contract Price $\left(\mathrm{w}_{\mathrm{ij}}\right)$ is a price mutually agreed between $\mathrm{i}^{\text {th }}$ vendor and $\mathrm{j}^{\text {th }}$ buyer which decide the profits of both vendor and buyer and hence it is considered as vital. Usually it lies between sales price and cost of manufacturing. Nature of the product, demand and logistic cost play critically in the fixation of contract price. The commodities that have good reputation and high demand are usually fast moving and involve low risk (probability of loss). In these circumstances, the buyer accepts the contract price closer to sales price, even with meager margin on the reasons stated as: Loss due to obsolescence is negligible; Non availability of the commodity results in loss of customers that would definitely reduce the overall turnover of the outlet; Storage/Holding cost is normally low. However in an another scenario, where the product is new and demand is not yet stabilized, the contract price is expected to settle at a lower level, closer to cost of production. The possible reasons are: Outlets of the commodity take the task of promoting the new product; Cost of inventory is expected to be high. In such cases, ethical issues like cooperation, revenue and knowledge sharing are needed to compete with the existing commodity and consolidate its market. The above discussions point out that contract price is a variable, which is dependent on location, competitiveness of the products and production and operational costs between vendor and buyer. This shows that contract price play a vital role in the context of revenue sharing.

\section{Vendor managed inventory}

The soft issues of SC models can be dealt through proper information sharing, communication and coordination between the stages of SC. Examples of collaborative and cooperative agreements come in many forms and by many names, including Continuous Replenishment (CR), Vendor Managed Inventory (VMI), Collaborative Forecasting, Planning and Replenishment (CFPR) and Information Sharing Programs (ISP). The overall goal shared by all these programs is to reduce costs and to increase efficiency in the SC by sharing the information and/or by the transfer of decision rights (Mishra \& Raghunathan, 2004; Fry, 2002; Ballou et al., 2000; Hammond, 1990). VMI is a proven concept for successful collaborative and cooperative agreements in SC. The core concept of VMI has been that the supplier monitors the customers' demand and inventory and replenishes that inventory as needed with no action on the part of the customer (Dong \& Xu, 2002 ; Disney \& Towill, 2002). Waller et al. (2001) noted that the main advantages of VMI were reduced costs and increased customer service levels to one or both of the participating members. VMI, however, has received very little attention in current operations' literature, particularly operations texts, but it has been widely recognized by industry leaders, such as Wal-Mart and the Campbell soup company for creating a competitive advantage. Franchise organizations have also made use of VMI to provide a higher level of operating efficiency 
(Williams, 2000). Cetinkaya \& Lee (2000) noted that, with VMI, inventory carrying costs were generally reduced, as were stock out problems while the approach offered the ability to synchronise inventory and transportation decisions. VMI has differed from a fixed-order interval model or a fixed-order quantity model in that neither the time nor the quantity of replenishment was necessarily fixed. The supplier was responsible for managing the inventory at the customer's location, generally using information technology, and for sending the correct amount at the correct time (Burke, 1996; Parks \& Popolillo, 1999). While research has been slowly increasing in the area of VMI, certain segments of business have appeared to be getting less attention than others (Latamore \& Benton, 1999). The SC's of large retail and manufacturing organizations have been the foci of most of the research. Mabert \& Venkataramanan (1998) pointed out that little work had been carried out in applying SCM techniques to service sectors. Therefore this chapter concentrates on VMI systems for two-echelon models in the service sectors.

\subsection{Mathematical representation of vendor operations and costs}

The relationship between two partners in any two-echelon supply chain model under VMI mode of operation with the various activities, mutual agreement, knowledge sharing and cooperation is shown in figure 7.

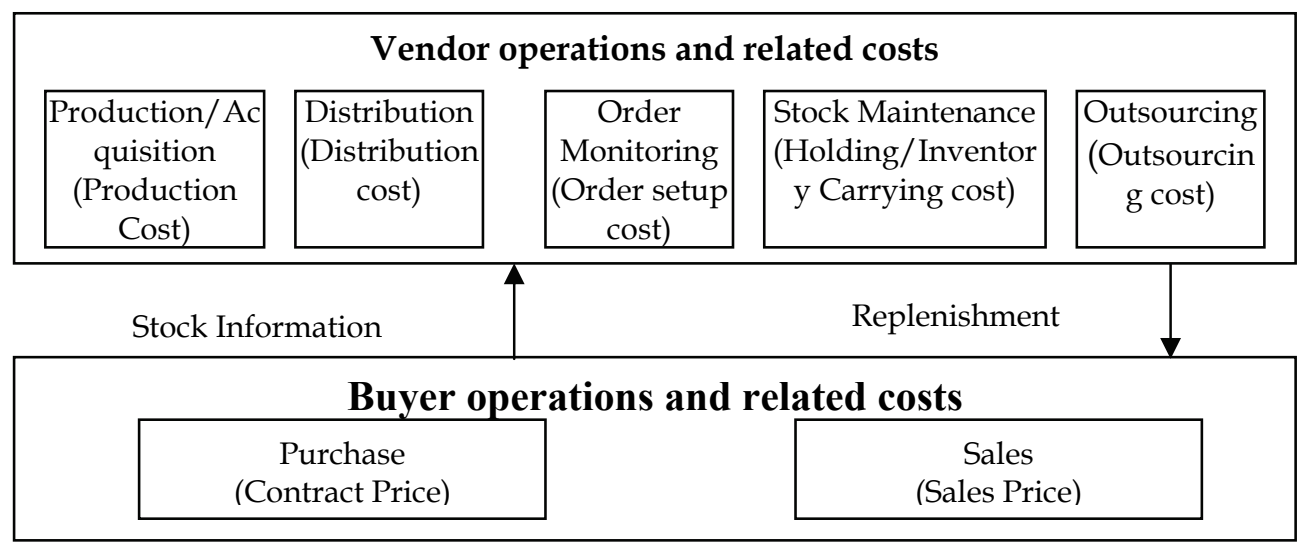

Figure 7. Operation mode of VMI systems with Outsourcing

\subsubsection{Responsibility of the vendor}

Vendor shares more responsibilities than buyer and acts as a leader. Vendor monitors, manages and replenishes inventory of buyer location (Achabal et al., 2000, Disney \& Towill, 2003). The costs associated with the above activities are: production cost, distribution cost and order setup cost stock maintenance cost and outsourcing cost if applicable.

Cost functions of the vendor

\section{Production and distribution cost}

Let ' $\delta_{\mathrm{i}}$ ' be the amount spent by a single vendor for producing a single unit. Then, the cost of production to meet the $j^{\text {th }}$ customer becomes ' $\delta_{i} y_{j}$ '. Distribution cost is the product of flow and transportation resource cost. Flow cost consists of the direct mileage and carrier contract cost per unit form $i^{\text {th }}$ vendor of the $j^{\text {th }}$ buyer ' $\theta_{i j}$ '. The transportation resource cost is the 
indirect cost such as the mode of transport, human router cost and administrative costs and termed as ' $\gamma_{i j}$ ' per unit demand for the $j^{\text {th }}$ buyer from $i^{\text {th }}$ vendor (Dong and $\mathrm{Xu}, 2002$ ). Therefore, the distribution cost $=\left(\theta_{i j} y_{i j}\right)\left(\gamma_{i j} y_{i j}\right)$. The distribution cost varies parabolically depending upon the increase in quantity and mode of transportation. Since in VMI mode, the vendor has to monitor inventory and to replenish products as and when required, there will be exponential variation in distribution cost depending upon the increase in quantity and mode of transportation.

\section{Order and stock maintenance cost}

$$
P D_{i j}=\delta_{i} y_{j}+\gamma_{i j} \theta_{i j} y_{j} 2
$$

The vendor monitors the stock status and replenishes the stock. The buyer does not initiate orders. Therefore the order / setup cost per replenishment ' $S_{i j V M I}$ ' associated with continuously monitoring the stock status is assumed to be the sum of order/setup cost of the vendor ' $S_{S i}$ ' and the order/setup cost of the buyer ' $S_{b j}$ ' (Dong \& Xu, 2002). Therefore cost involved to replenish the batches ' $Q_{i j}$ ' of demand of the $j^{\text {th }}$ buyer ' $y_{j}$ ' is given as Order / setup cost for replenishment $=\left(\left(S_{S i}+S_{b j}\right) y_{j} / Q_{i j}\right)$.

Inventory, whatever is the mode of operation, is held at both vendor and buyer locations $H_{S i}$ and $H_{b j}$ are the cost of holding one unit per unit time at the $i^{\text {th }}$ vendor and the $j^{\text {th }}$ buyer's location respectively. In order to replenish $Q_{i j}$ to buyer ' $j$ ' the vendor ' $i$ ' accumulates this before delivery. Therefore the vendor ' $i$ ' holds an average inventory of $Q_{i j} / 2$ to replenish buyer ' $j$ ' and VMI cost of holding inventory $\left(H_{i j V M I}\right.$ ) becomes the sum of $H_{S i}$ and $H_{b j}$ (Dong \& $\mathrm{Xu}, 2002)$. Therefore the stock maintenance cost is given as $\left(H_{S i}+H_{b j}\right) Q_{i j} / 2$.

Thus the order and stock maintenance cost $O S M_{i j}$ of the vendor is the sum of the order setup cost and the average inventory holding cost and is as follows:

$$
\mathrm{OSM}_{\mathrm{ij}}=\left(\mathrm{S}_{\mathrm{Si}}+\mathrm{S}_{\mathrm{bj}}\right) \mathrm{y}_{\mathrm{j}} / \mathrm{Q}_{\mathrm{ij}}+\left(\mathrm{H}_{\mathrm{Si}}+\mathrm{H}_{\mathrm{bj}}\right) \mathrm{Q}_{\mathrm{ij}} / 2
$$

In this mode of operation the replenishment process takes place instantaneously, therefore to minimize the $O S M_{i j}$, Economic Order Quantity $\left(E O Q_{i j}\right)$ for buyer is determined by equating the first differential of $O S M_{i j}$ to zero.

$$
\begin{gathered}
\mathrm{d}\left(\mathrm{OSM}_{\mathrm{ij}}\right) / \mathrm{dQ}_{\mathrm{j}}=0 \\
\mathrm{EOQ}_{\mathrm{ij}}=\left[2\left(\mathrm{~S}_{\mathrm{Si}_{\mathrm{i}}}+\mathrm{S}_{\mathrm{bj}}\right) \mathrm{y}_{\mathrm{j}} /\left(\mathrm{H}_{\mathrm{Si}_{\mathrm{i}}}+\mathrm{H}_{\mathrm{bj}}\right)\right]^{1 / 2}
\end{gathered}
$$

Substituting $E O Q_{j}$ for $Q_{j}$, in equation (3)

\section{Outsourcing cost:}

$$
\mathrm{OSM}_{\mathrm{ij}}=\left[2\left(\mathrm{H}_{\mathrm{Si}}+\mathrm{H}_{\mathrm{bj}}\right)\left(\mathrm{S}_{\mathrm{Si}}+\mathrm{S}_{\mathrm{bj}}\right) \mathrm{y}_{\mathrm{j}}\right]^{1 / 2}
$$

Whenever, the aggregate sales quantity $\left(\sum_{j=1}^{n} y_{j}\right)$ of all the buyers exceeds the capacity ' $C$ ' of the vendor, then the vendor has to outsource the extra quantities ' $o_{y}^{\prime}$ ( $\left.=\sum_{j=1}^{n} y_{j}{ }^{-C}\right)$. It is assumed that an additional cost incurred for vendor to outsource a unit is ' $\eta$ ' times of unit production cost ' $\delta$ '.

There fore outsourcing 


$$
\mathrm{o}_{\mathrm{c}}=\beta \eta \delta\left(\sum_{j=1}^{n} y_{j}-\mathrm{C}\right)
$$

Where,

$$
\begin{aligned}
& \beta=1, \text { if }\left(\sum_{j=1}^{n} y_{j}-\mathrm{C}\right)>0 \\
& \beta=0, \text { if }\left(\sum_{j=1}^{n} y_{j}{ }^{-C}\right)<0
\end{aligned}
$$

In case of multiple buyers, the outsourcing cost is equally distributed to each buyer when calculating the vendor profit and contract prices for individual buyer ' $j$ ' which is given as, For ' $n$ ' number of buyers outsourcing cost

$$
\text { ' } \mathrm{o}_{\mathrm{cj}}{ }^{\prime}=\beta \eta \delta\left(\sum_{j=1}^{n} y_{j}{ }^{-\mathrm{C}}\right) / \mathrm{n}
$$

The profit of Vendor ' $P_{s j}$ ' when supplying the product to $j^{\text {th }}$ buyer is the difference between revenue to the vendor and the total cost involved, which is represented as

$$
P_{\mathrm{sj}}=\mathrm{W}_{\mathrm{ij}} \mathrm{y}_{\mathrm{j}}-\mathrm{PD}_{\mathrm{ij}}-\mathrm{OSM}_{\mathrm{ij}}-\mathrm{o}_{\mathrm{cj}}
$$

Therefore the total profit to the vendor $P_{s}$ by supplying the products to all buyers is as follows:

$$
\mathrm{P}_{\mathrm{s}}=\sum_{j=1}^{n} P_{s j}=\sum_{\mathrm{j}=1}^{\mathrm{n}}\left\{\mathrm{W}_{\mathrm{ij}} \mathrm{y}_{\mathrm{j}}-\left(\delta_{\mathrm{i}} \mathrm{y}_{\mathrm{j}}+\gamma_{\mathrm{ij}} \theta_{\mathrm{ij}} \mathrm{y}_{\mathrm{j}}{ }^{2}\right)-\left[\left(2\left(\mathrm{H}_{\mathrm{i} j \mathrm{VMI}}\right)\left(\mathrm{S}_{\mathrm{ij} \mathrm{VMI}}\right) \mathrm{y}_{\mathrm{j}}\right)^{1 / 2}-\left(\left(\beta \eta \delta\left(\sum_{j=1}^{n} y_{j}{ }^{-\mathrm{C}}\right)\right) / \mathrm{n}\right)\right]\right\}
$$

\subsubsection{Buyer operation and costs}

The buyer acts as an agent for the vendor and provides space to sell the products. Since the buyer deals with multiple products, maintenance costs are assumed to be negligible for a single product. Therefore the only cost associated with the buyers in VMI mode is the cost of purchase which depends on contract price. It is generally believed that acceptable (fair) pricing to the partners involved is an important factor for better relations in VMI and it requires acceptable contract price to be agreed that would satisfy both the vendor and the buyer (Grieger, 2003). The main focus of revenue sharing is to share the revenues/profits ' $P R_{i j}$ ' generated based on the assignments and responsibilities in order to avoid the conflict between SC partners (Maloni \& Benton, 1997). This reveals that revenue sharing between vendor and buyer plays a vital role in fixing the contract price. Thus the profit of a buyer ' $\mathrm{P} b_{j}$ ' in VMI mode is the difference between sales revenue and the cost of purchase and is represented as:

$$
P b_{j}=P\left(y_{j}\right) y_{j}-W_{i j} y_{j}
$$

Substituting $\mathrm{P}\left(\mathrm{y}_{\mathrm{j}}\right)$ from equation 1 , 


$$
P b_{j}=\left(a_{j}-b_{j} y_{j}\right) y_{j}-W_{i j} y_{j}
$$

For the known revenue share ratio $\left(P R_{i j}=P s_{j} / P b_{j}\right)$ between the vendor ' $i$ ' and buyer ' $j$ ' the contract price can be derived as:

$$
\mathrm{W}_{\mathrm{ij}}=\left\{\mathrm{a}_{\mathrm{j}} \mathrm{y}_{\mathrm{j}} \mathrm{PR}_{\mathrm{j}}-\mathrm{b}_{\mathrm{j}} \mathrm{y}_{\mathrm{j}}^{2} \mathrm{PR}_{\mathrm{j}}+\delta y_{j}+\gamma_{j} \theta_{j} y_{j}^{2}+\left[\left(2\left(\mathrm{H}_{\mathrm{j}_{V M I}}\right)\left(\mathrm{S}_{\mathrm{jVMI}}\right) \mathrm{y}_{\mathrm{j}}\right)^{1 / 2}-\left(\left(\left(\beta \eta \delta\left(\sum_{j=1}^{n} y_{j}-\mathrm{C}\right)\right) / \mathrm{n}\right)\right]\right\} \div\left[\left(1+\mathrm{PR}_{\mathrm{j}}\right) y_{j}\right](10\right.
$$

\section{Objective}

The turnover and profit of an organisation depend on the price and demand of its products. The reasons for the non purchase of preferred commodities by customers are: $59 \%$ too expensive; $8 \%$ disliked appearance; $12 \%$ shelf life too short and $3 \%$ inconsistent quality (Tronstad, 1995). Most of the models on pricing focus on profit generation at single level (Rajan et al., 1992; Gallego \& Vanryzin, 1994; Polatoglu, 1991; Desarbo et al., 1987). Manufacturers fix price to the wholesaler which is known as supply price, considering manufacturing and distribution costs. Wholesaler offers a price to the retailer based on money turnover / commission. The retailer sells at a price depending upon market conditions. Hence pricing is an essential component of a product which makes customer more sensitive. Rather, trial and error method is often followed in organizations which involve finding out customer demand and other influential parameters such as market share, economic conditions, manufacturing capacity, nature of the product, inventory costs, cyclic fluctuations in cost and demand and rapid deterioration of product. Pricing mechanism differs with nature of the product (perishable, storable, seasonal, etc.,), government regulations (duties, licensing, etc.) and type of market (monopoly, oligopoly etc.) (Klastorin, 2004). The conventional trial and error pricing mechanism may not yield fruitful solution to SC scenario, in which all the entities need to work together in order to meet the global competition (i.e., between supply chains) in the market for long term (Casati et al., 2001). Under the light of the stated issues, this chapter deals with the pricing mechanism in a SC models.

Two vital parameters that govern the operation of a SC are: sales price at buyers market and contract price between vendor and buyer. Sales price is significant in the sense that it determines the overall profit of the supply chain, referred here as channel profit. The existence of partnership relies on contract price. It is generally believed that pricing acceptable (fair) to the partners involved is an important factor for better relations in VMI and that it requires optimal sales and contract prices that would satisfy both vendor and buyer (Grieger, 2003). No partner would compromise on due share of profit. Besides, revenue sharing is the concept in which total channel profit should be allocated among SC participants in different profit ratios (Giannoccaro \& Pontrandolfo, 2004). The main focus of revenue sharing is to share the revenues/profits generated based on the assignments and responsibilities in order to avoid the conflict between SC partners (Maloni \& Benton, 1997). Min \& Zhou (2002) pointed out that profit sharing is believed as one of the major behavioural (soft) issues in strengthening the relationship between partners of SC to improve the performance. Gjerdrum et al. (2002) pointed out that fair optimized profit 
distribution between the partners would lead to better relationship and only this kind of distribution can be the genuine deal

In general the contract price dictated by the vendor will be higher for most acceptable (fair) product for which demand is high, since there is low risk involved to the buyers and therefore the revenue share to the vendor will be normally high or equal. On the other hand, for the newly launched product, contract price dictated by the vendor will be meager, since the buyer takes the responsibility of promoting the sale of the product and therefore the revenue share to the buyer will be very high. This reveals that the contract price plays a vital role in VMI context of revenue sharing. Moreover, fixation of contract price for the different revenue ratio is a tedious process, which leads to conflicts between partners if it is not properly adopted (Gjerdrum et al., 2002). It is evident from the above discussion that the contract and sales prices, which determine the profits of buyer, vendor and channel (sum of buyer and vendor profit), are the key parameters for the successful adaptation of VMI..

Members of SC addressed as partners, promote and adopt strategies to minimize cost or maximize turnover. The traditional objective of the supply chain is to minimize total supply chain cost to meet the given demand. Researchers argue that total cost minimization is an inappropriate and timid objective for the firm to pursue when it analyses its strategic and tactical supply chain plans (Shapiro, 2001; Gjerdrum et al., 2002). Instead maximization of net revenue could be considered as appropriate objective to supply chain. In the literature on Supply Chain Management (SCM), the net revenue is addressed as channel profit $P_{c}^{\prime}$. Therefore determination of optimal sales quantity $\left(y_{j o p t}\right)$ for each buyer $j$, which maximizes the $P_{c}{ }^{\prime}$ becomes the objective of this chapter. The sales price $P\left(y_{j o p t}\right)$ and contract price $W_{\text {jopt }}$ could be subsequently derived with the ' $y_{\text {jopt }}$ ' obtained through various heuristics. Concerning the above, this chapter determine the optimal prices (contract and sales prices) for maximum channel profit in SC models operating under VMI mode of operation.

The objective of VMI systems, in general are: inventory reduction and increased responsiveness. Both of them are aimed to increase the channel profit (ethical optimisation). Besides, a fair revenue share between vendor and buyer would strengthen the partnership in SC model. These two factors (channel profit and revenue share) are considered as the objectives of the model. The problem is stated as:

\section{Determination of}

i. optimal combination of sales quantity' $\mathrm{yjopt}^{\prime}$ (for $\forall \mathrm{j}$ ) for maximum channel profit ' $\mathrm{Pc}^{\prime}$ of two echelon supply chain operating in VMI mode of operation and

ii. Operating parameters such sales prices ' $\mathrm{P}(\mathrm{yj})$ ' (for $\forall \mathrm{j}$ ) corresponding to ' $\mathrm{y}$ jopt ' and acceptable contract prices $\mathrm{Wj}$ (for $\forall \mathrm{j}$ ) under different revenue shares 'PRj'(for $\forall \mathrm{j}$ ) and outsourcing quantity 'oy' for vendor (if applicable), given the following:

- $\quad$ production cost per unit ' $\delta_{\mathrm{i}}$ ' (for $\forall \mathrm{i}$ )

- $\quad$ flow cost per unit ' $\theta_{\mathrm{ij}}$ ' (for $\forall \mathrm{i}$, for $\forall \mathrm{j}$ )

- intercept ' $\mathrm{a}_{\mathrm{j}}$ ' (for $\forall \mathrm{j}$ ) of demand function

- cost slope ' $b_{j}^{\prime}$ (for $\forall j$ ) of demand function

- $\quad$ order / setup cost of vendor ' $\mathrm{S}_{\mathrm{si}}$ ' (for $\forall \mathrm{i}$ ) and buyer ' $\mathrm{H}_{\mathrm{bj}}$ ' (for $\forall \mathrm{j}$ )

- $\quad$ holding cost of vendor ' $\mathrm{H}_{\mathrm{si}}$ ' (for $\forall \mathrm{i}$ )and buyer ' $\mathrm{H}_{\mathrm{bj}}$ ( for $\forall \mathrm{j}$ )

- $\quad$ capacity of the vendor ' $\mathrm{C}_{\mathrm{i}}$ ' (for $\forall \mathrm{i}$ )

- Outsourcing cost constant ' $n$ '

- $\quad$ sales quantity range $y_{j m i n}$ and $y_{j m a x}($ for $\forall j$ ) and 
- $\quad$ revenue share ratio ' $\mathrm{PR}_{\mathrm{ij}}$ ' (for $\forall \mathrm{I}$, for $\forall \mathrm{j}$ ) between vendor and buyer.

\subsection{Mathematical model for SV_SB}

The mathematical model for SV_SB is given below

\subsubsection{Optimal sales quantity}

Maximize

Subject to:

$$
\mathrm{P}_{\mathrm{c}}=\left\{\mathrm{Wy}-\left(\delta \mathrm{y}+\gamma \theta \mathrm{y}^{2}\right)-\left[\left(2\left(\mathrm{H}_{\mathrm{VMI}}\right)\left(\mathrm{S}_{\mathrm{VMI}}\right) \mathrm{y}\right)^{1 / 2}\right]\right\}
$$

$$
\begin{aligned}
& y_{\min } \leq y \leq y_{\max } \text { (Buyer sales quantity constraints) } \\
& y_{\min } \leq C \leq y_{\max } \quad \text { (Vendor capacity constraints) } \\
& y_{j} \geq 0 \quad \text { (Non-negative Constraint \& Integer) }
\end{aligned}
$$

The solution to the above problem provides the optimal sales quantity ' $y_{\text {opt }}$ '

\subsubsection{Optimal sales price}

Optimal sales price is calculated by using equation (1)

$$
\mathrm{P}\left(\mathrm{y}_{\mathrm{opt}}\right)=\mathrm{a}-\mathrm{b}_{\mathrm{j}} \mathrm{y}_{\mathrm{opt}} \text {. }
$$

\subsubsection{Acceptable contract price}

The acceptable contract price ' $W_{\text {opt }}$ ' is arrived at by substituting the optimal sales quantity ' $y_{\text {opt }}$ ' in the equation

$$
\mathrm{W}_{\text {opt }}=\frac{\mathrm{ay}_{\mathrm{opt}} \mathrm{PR}-\mathrm{by}^{2} \mathrm{PR}+\delta y_{\text {opt }}+\gamma \theta y_{\text {opt }}{ }^{2}+\left(2\left(H_{V M I}\right)\left(S_{V M I}\right) y_{\text {opt }}\right]^{1 / 2}}{(1+\mathrm{PR}) \mathrm{y}_{\text {opt }}}
$$

\subsection{Mathematical model for SV_MB}

The mathematical model for SV_MB is given below

\subsubsection{Optimal sales quantity}

Maximize

$$
\mathrm{P}_{\mathrm{c}}=\sum_{j=1}^{n}\left\{a_{\mathrm{j}} \mathrm{y}_{\mathrm{j}}-\mathrm{b}_{\mathrm{j}} \mathrm{y}_{\mathrm{j}}{ }^{2}-\delta \mathrm{y}_{\mathrm{j}}-\gamma_{\mathrm{j}} \theta_{\mathrm{j}} \mathrm{y}_{\mathrm{j}}^{2}-\left[2\left(\mathrm{H}_{\mathrm{jVMI}}\right)\left(\mathrm{S}_{\mathrm{jVMI}}\right) \mathrm{y}_{\mathrm{j}}\right]^{1 / 2}\right\}
$$

Subject to:

$$
y_{j \min } \leq y_{j} \leq y_{j \max }(\text { for } \forall j) \text { (Buyer sales quantity constraints) }
$$




$$
\begin{aligned}
& \sum_{j=1}^{n} \sum_{\mathrm{y}_{j \min } \leq \mathrm{C} \leq \mathrm{y}_{\mathrm{j} \max } \quad \text { (Vendor capacity constraints) }}^{n} \\
& y_{j} \geq 0 \quad \text { (Non-negative Constraint \& Integer) }
\end{aligned}
$$

The solution to the above problem provides optimal sales quantity ' $y_{\text {jopt }}$ ' (for $\forall j$ )

\subsubsection{Optimal sales price}

The optimal sales price $\left(P\left(y_{j o p t}\right)\right)$ is derived by substituting the optimal sales quantity $\left(y_{j o p t}\right)$ in equation (1) as furnished below.

$$
P\left(y_{j o p t}\right)=a_{j}-b_{j} y_{j o p t}
$$

\subsubsection{Acceptable contract price}

The acceptable contract price ' $W_{\text {jopt }}$ ' is derived by substituting the optimal sales quantity ' $y_{\text {jopt }}$ ' in the equation (10).

$$
\mathrm{W}_{\mathrm{j}_{\mathrm{opt}}}=\frac{\mathrm{a}_{\mathrm{j}} \mathrm{y}_{\mathrm{jopt}} \mathrm{PR}_{\mathrm{j}}-\mathrm{b}_{\mathrm{j}} \mathrm{y}_{\mathrm{jopt}}{ }^{2} \mathrm{PR} \mathrm{R}_{\mathrm{j}}+\delta y_{j o p t}+\gamma_{\mathrm{j}} \theta_{j} y_{\text {jopt }}^{2}+\left(2\left(H_{i V M I}\right)\left(S_{i V M I}\right) y_{\text {jopt }}\right)^{1 / 2}}{\left(1+\mathrm{PR}_{\mathrm{j}}\right) \mathrm{y}_{j o p t}}
$$

\subsection{Mathematical model for SV_MBO}

The mathematical model for SV_MBO is given below

\subsubsection{Optimal sales quantity}

$$
\operatorname{Max} \mathrm{P}_{\mathrm{c}}=\sum_{j=1}^{n}\left\{a_{\mathrm{j}} \mathrm{y}_{\mathrm{j}}-\mathrm{b}_{\mathrm{j}} \mathrm{y}_{\mathrm{j}}{ }^{2}-\delta \mathrm{y}_{\mathrm{j}}-\gamma_{\mathrm{j}} \theta_{\mathrm{j}} \mathrm{y}_{\mathrm{j}}{ }^{2}-\left[\left(2\left(\mathrm{H}_{\mathrm{jVMI}}\right)\left(\mathrm{S}_{\mathrm{j} V M I}\right) \mathrm{y}_{\mathrm{j}}\right)^{1 / 2}-\left(\left(\beta \eta \delta\left(\sum_{j=1}^{n} y_{j}-\mathrm{C}\right)\right) / \mathrm{n}\right)\right]\right\}
$$

Subject to

$$
\begin{aligned}
y_{j \min } \leq \mathrm{y}_{\mathrm{j}} \leq \mathrm{y}_{\mathrm{jmax}}(\forall \mathrm{j}) \text { (Buyer demand constraints) } \\
y_{j} \geq 0 \quad \text { (Non-negative Constraint \& Integer) }
\end{aligned}
$$

The solution to the above problem provides the optimal combination of sales quantities ' $y_{\text {jopt }}$ ' $(\forall j)$.

\subsubsection{Optimal outsourcing quantity}

Optimal outsourcing quantity is difference between sums of all buyers' optimal sales quantity and the capacity of the vendor which is given as,

$$
\begin{aligned}
\text { oy opt } & =\sum_{j=1}^{\mathrm{n}}\left\{\mathrm{y}_{\text {jopt }}\right\}-C \quad \text { if } \beta=1 \\
& =0 \quad \text { if } \quad \beta=0
\end{aligned}
$$




\subsubsection{Optimal sales price}

Optimal sales price is calculated by using equation (1)

$$
P\left(y_{\text {jopt }}\right)=a_{j}-b_{j} y_{j o p t}(\forall j) \text {. }
$$

\subsubsection{Acceptable contract price}

The acceptable contract price $W_{\text {jopt }}$ is derived by substituting the optimal sales quantity ' $y_{\text {jopt }}$ ' and optimal outsourcing quantity ' $o_{\text {yopt }}$ ' in the equation 10.

$$
\begin{aligned}
& \mathrm{W}_{\mathrm{jopt}}=\left\{\mathrm{a}_{\mathrm{j}} \mathrm{y}_{\mathrm{j}_{\mathrm{opt}}} \mathrm{PR}_{\mathrm{j}}-\mathrm{b}_{\mathrm{j}} \mathrm{y}_{\mathrm{jopt}}{ }^{2} \mathrm{PR}_{\mathrm{j}}+\delta y_{j o p t}+\gamma_{\mathrm{j}} \theta_{j} y_{\text {jopt }}{ }^{2}+\right. \\
& \left.+\left[\left(2\left(\mathrm{H}_{\mathrm{j}_{V M I}}\right)\left(\mathrm{S}_{\mathrm{jVMI}}\right) \mathrm{y}_{\mathrm{jopt}}\right)^{1 / 2}-\left(\left(ß \eta \delta\left(\sum_{j=1}^{n} y_{j_{\mathrm{opt}}}-\mathrm{C}\right)\right) / \mathrm{n}\right)\right]\right\} \div\left[\left(1+\mathrm{PR}_{\mathrm{j}}\right) * y_{j o p t}\right]
\end{aligned}
$$

\subsection{Mathematical model for MV_MB}

Sales quantity of the $j^{\text {th }}$ buyer $y_{j}=\sum_{i=1}^{m} x_{i j}$, where $x_{i j}$ is the transaction quantity between $i^{\text {th }}$ vendor and $j^{\text {th }}$ buyer

\subsubsection{Optimal transaction quantity}

Maximize

$$
\mathrm{P}_{\mathrm{c}}=\sum_{j=1}^{n}\left\{a_{\mathrm{j}} \sum_{i=1}^{m} x_{i j}-\mathrm{b}_{\mathrm{j}}\left(\sum_{i=1}^{m} x_{i j}\right)^{2}\right\}-\sum_{i=1}^{m} \sum_{j=1}^{n}\left\{\delta_{\mathrm{i}} \mathrm{x}_{\mathrm{ij}}+\gamma_{\mathrm{j}} \theta_{\mathrm{ij}} \mathrm{x}_{\mathrm{ij}}{ }^{2}+\left[2\left(\mathrm{H}_{\mathrm{ijVMI}}\right)\left(\mathrm{S}_{\mathrm{ijVMI}}\right) \mathrm{x}_{\mathrm{ij}}\right]^{1 / 2}\right\}
$$

Subject to:

$$
\begin{gathered}
y_{j \min } \leq \mathrm{y}_{\mathrm{j}} \leq \mathrm{y}_{\mathrm{jmax}}(\text { for } \forall \mathrm{j}) \text { (Buyer sales constraints) } \\
\sum_{j=1}^{n} y_{j \min } \leq C_{i} \leq \sum_{j=1}^{n} y_{j \max }(\text { for } \forall j) \text { (Vendor capacity constraints) } \\
y_{j} \geq 0 \text { (Non-negative Constraint \& Integer) }
\end{gathered}
$$

The solution to the above problem provides optimal transaction quantity ' $x_{i j o p t}$ (for $\forall i, \forall j$ )

\subsubsection{Optimal sales price}

The optimal sales price ' $P\left(y_{\text {jopt }}\right)$ ' is derived by substituting the optimal transaction quantity ' $x_{i j o p t}$ ' in equation (1) as furnished below. Optimal sales quantity of the $j^{\text {th }}$ buyer 


$$
\begin{gathered}
y_{j o p t}=\sum_{i=1}^{m} x_{i j o p t} \\
\mathrm{P}\left(\mathrm{y}_{j o p t}\right)=\mathrm{a}_{\mathrm{j}}-\mathrm{b}_{\mathrm{j}} \mathrm{y}_{j o p t}
\end{gathered}
$$

\subsubsection{Acceptable contract price}

The acceptable contract price ' $W_{i j o p t}$ is derived by substituting the optimal transaction quantity ' $x_{\text {ijopt }}$ ' in the equation (10)

$$
W_{i j o p t}=\frac{\mathrm{a}_{\mathrm{j}} \mathrm{x}_{\mathrm{ijopt}} \mathrm{PR}_{\mathrm{ij}}-\mathrm{b}_{\mathrm{j}} \mathrm{x}_{\mathrm{ijopt}}{ }^{2} \mathrm{PR}_{\mathrm{ij}}+\delta_{i} x_{i j o p t}+\gamma_{j} \theta_{i j} x_{i j o p t}{ }^{2}+\left(2\left(H_{i j V M I}\right)\left(S_{i j V M I}\right) x_{i j o p t}\right)^{1 / 2}}{\left(1+\mathrm{PR}_{\mathrm{ij}}\right) \mathrm{x}_{\mathrm{ijopt}}}
$$

\subsection{Mathematical model for MV_MBO}

\subsubsection{Optimal transaction quantity}

$$
\text { Maximize } P_{c}=\sum_{j=1}^{n}\left\{a_{j} \sum_{i=1}^{m}\left(x_{i j}+O x_{i j}\right)-b_{j}\left(\sum_{i=1}^{m}\left(x_{i j}+O x_{i j}\right)^{2}\right\}-\sum_{i=1}^{m} \sum_{j=1}^{n}\left\{\delta_{i}\left(x_{i j}+O x_{i j}\right)+\gamma_{i j} \theta_{i j}\right.\right.
$$

Subject to:

$$
\left.\left(\mathrm{x}_{\mathrm{ij}}+\mathrm{Ox} \mathrm{x}_{\mathrm{ij}}\right)^{2}+\left[2\left(\mathrm{H}_{\mathrm{ij} V M I}\right)\left(\mathrm{S}_{\mathrm{ijVMI}}\right) \mathrm{x}_{\mathrm{ij}}\right]^{1 / 2}+\left(\lambda_{\mathrm{i}}\left(\delta_{\mathrm{i}} \mathrm{O} \mathrm{x}_{\mathrm{ij}}+\gamma_{\mathrm{ij}} \theta_{\mathrm{ij}} \mathrm{O} \mathrm{x}_{\mathrm{ij}}{ }^{2}\right)\right)\right\}
$$

$$
\begin{gathered}
\sum_{i=1}^{m}\left(x_{i j m i n}+O x_{i j m i n}\right) \leq \sum_{i=1}^{m}\left(x_{i j}+O x_{i j}\right) \leq \sum_{i=1}^{m}\left(x_{i j \max }+O x_{i j m a x}\right) \\
(\text { for } \forall j) \quad \text { (Buyer sales constraints) } \\
\sum_{i=1}^{m}\left(x_{i j}+O x_{i j}\right) \geq 0 \text { (Non- negative Constraint \& Integer) }
\end{gathered}
$$

The solution to the above problem provides optimal transaction quantity ' $x_{i j o p t}$ (for $\left.\forall i, \forall j\right)$

\subsubsection{Optimal outsourcing transaction quantity}

The optimal outsourcing transaction quantity is derived as follows:

$$
\mathrm{Ox}_{\mathrm{ijopt}}=\beta_{\mathrm{ij}}\left(\mathrm{y}_{\mathrm{j}^{-}} \sum_{i=1}^{m} \mathrm{x}_{\mathrm{ijopt}}\right)
$$

where,

For every buyer ' $\mathrm{j}$ ' $\beta_{\mathrm{ij}}=1$; if the profit ratio with vendor ' $\mathrm{i}$ ' is lowest; otherwise $\beta_{\mathrm{ij}}=0$; 


\subsubsection{Optimal sales price}

The optimal sales price ' $\mathrm{P}\left(\mathrm{y}_{\text {jopt }}\right)$ ' is derived by substituting ' $\mathrm{x}_{\mathrm{ijopt}}$ ' and 'Ox $\mathrm{x}_{\mathrm{ijopt}}$ ' in equation (1) as furnished below.

Optimal sales quantity of the $j^{\text {th }}$ buyer

$$
\begin{gathered}
y_{j o p t}=\sum_{i=1}^{m}\left(X_{i j o p t}+O x_{\text {ijopt }}\right) \\
\mathrm{P}\left(\mathrm{y}_{\text {jopt }}\right)=\mathrm{a}_{\mathrm{j}}-\mathrm{b}_{\mathrm{j}} \mathrm{y}_{\text {jopt }}(\text { for } \forall \mathrm{j})
\end{gathered}
$$

\subsubsection{Acceptable contract price}

The acceptable contract price ' $W_{i j o p t}$ ' is derived by substituting the optimal transaction quantity ' $x_{\mathrm{ijopt}}$ ' and Outsourcing transaction quantity ' $O x_{i j o p t}$ ' in the equation 10.

$$
\begin{gathered}
W_{i j o p t}=\frac{\mathrm{a}_{\mathrm{j}}\left(\mathrm{x}_{\mathrm{ij} \text { opt }}+\mathrm{Ox}_{\mathrm{ijopt}}\right) \mathrm{PR}_{\mathrm{ij}}-\mathrm{b}_{\mathrm{j}}\left(\mathrm{x}_{\mathrm{ijopt}}+O x_{i j o p t}\right)^{2} \mathrm{PR}_{\mathrm{ij}}+\delta_{i}\left(x_{i j o p t}+O x_{i j o p t}\right)+}{\left(1+\mathrm{PR}_{\mathrm{ij}}\right)\left(\mathrm{x}_{\mathrm{ijopt}}+O x_{i j o p t}\right)} \\
+\gamma_{i j} \theta_{i j}\left(x_{i j o p t}+O x_{i j o p t}\right)^{2}+\left(2\left(H_{i j V M I}\right)\left(S_{i j V M I}\right) x_{i j o p t}\right]^{1 / 2}+\lambda_{i}\left(\delta_{i} O x_{i j o p t}+\gamma_{i j} \theta_{i j} O x_{i j o p t}{ }^{2}\right) \\
\left(1+\mathrm{PR}_{\mathrm{ij}}\right)\left(\mathrm{x}_{\mathrm{ijopt}}+O x_{i j o p t}\right)
\end{gathered}
$$

\section{Heuristics}

Many well-known algorithmic advances in optimization have been made, but it turns out that most of them have not had the expected impact on the decisions for designing and optimizing supply chain related problems (Shapiro, 2001). For example, some optimization techniques are of little use because they are not well suited to solve complex real logistics problems in the short time, needed to make decisions. Also some techniques are highly problem-dependent and need high expertise. All the constraints of the problem may not be amenable to the mathematical articulation without such an articulation optimization may not be possible leaving the decision maker with no choice but to resort to his own experience. This adds difficulties in the implementations of optimization algorithms in the DSS which contradict the tendency to fast implementation in a rapid changing world. Alternatively for many of the problems, since the cost to find an optimal solution is so high, heuristic problem solving would suffice. Therefore, on the one hand there is the need for sophisticated logistics Decision Support System (DSS) to enable the organizations to respond quickly to new issues and problems faced on the SCM, and on the other hand there are advances in the area of heuristics that can provide an effective response to complex problems. This provides a fertile ground for applications of these techniques to SCM and subsequently of the development of computer based systems to help logistics decisions. Well-designed heuristics packages can maintain their advantage over optimization packages in terms of computer resources required, a consideration unlikely to diminish in importance so long as the size and complexity of the models arising in practice continue to increase. This is true for many areas in the firm, but especially to SCM related problems. 
A heuristic algorithm (often shortened to heuristic) is a solution method that does not guarantee an optimal solution, but, in general, has a good level of performance in terms of solution quality and convergence. To develop a heuristic for a particular problem, some problem-specific characteristics must be defined. The problem-specific may include the definition of a feasible solution, the neighbourhood of a solution, rules for changing solutions, and rules for setting certain parameters during the course of execution (Corne et al.,1999; Glover \& Gkochenberger, 2001). In fact, some of the most popular commercial packages use heuristic methods or rules of thumb. Heuristic may be constructive (producing a single solution) or local search (starting from one or given random solutions and moving iteratively to other nearby solutions) or a combination (constructing one or more solutions and using them to start a local search).

The area of heuristic techniques has been the object of intensive studies in the last decades. Recent advances in heuristic technique include meta-heuristics, which gained widespread applications along with the computational power of the computer technology. A metaheuristic is a framework for producing heuristics, such as Simulated Annealing (SAA), Genetic Algorithm (GA), Tabu Search (TS), Particle Swarm Optimisation (PSO), Ant Colony Optimisation (ACO), etc. (Yokota et al., 1996; Costa \& Oliveira 2001; Wu, 2001). Metaheuristics have many desirable features for becoming an excellent method: in general they are simple, easy to implement, robust and have been proven highly effective to solve hard problems. Even in their most simpler and basic implementation, the meta-heuristics have been able to effectively solve very hard and complex problems. There are several aspects which are worth enough to be mentioned. The most important one is the meta-heuristics modular nature that leads to short development times and updates, given a clear advantage over other techniques for industrial applications.

The other important aspect is that the amount of data involved in any optimization model for an integrated supply chain problem can be overwhelming. The complexity of the models for the SCM and the incapacity for solving in real time some of them by the traditional techniques force the use of the obvious techniques to reduce this complex issue by data aggregation (Simchi-Levi et al., 2000). Therefore, instead of aggregating data to be able to obtain a simple and solvable model, but which will not represent well the reality, researchers should consider the complex model by using an approximation algorithm. The scenario-based approaches can incorporate a meta-heuristic to obtain the best possible decision within a scenario. The combination of best characteristics of human decisionmaking and computerised model and algorithmic based systems into interactive and graphical design frameworks have proven to be very effective in SCM, since many supply chain problems are new, subject to rapid changes and moreover, there is no clear understanding of all of the issues involved.

Rutenbar (1989) pointed out that simple heuristics is not capable of solving the hard problems with either numerous, contradictory constraints, or complex, baroque cost functions with respect to solution quality and execution time whereas meta heuristics such as GA and SAA are most suitable. SAA and GA are widely used for combinatorial optimization problems in different domains such as location, packing, partitioning and scheduling etc. SAA is a technique for combinatorial optimization problems, such as minimizing functions of very many variables. Because many real-world design problems can be cast in the form of such optimization problems, there is intense interest in general techniques for their solution. SAA is one such technique of rather recent vintage with an unusual pedigree: it is motivated by an analogy to the statistical mechanics of annealing in 
solids. GA makes no assumptions about the function to be optimized. All that a GA requires is a performance measure, some form of problem representation, and operators that generate new population members. This general approach has been applied to many difficult and novel optimization problems. GA's strength is its robustness, wide domain of applicability and global search capability. This modular aspect is especially important in implementing a DSS in a firm and the rapid changes that occur in the area of SCM. Lourenço (2005) pointed out that meta-heuristics, when incorporated to a DSS for SCM, can contribute significantly to the decision process, especially taking into consideration the increased complexity of the logistics problems previously presented. DSS, based on metaheuristics, are not currently widespread, but it appears to be growing as a potential technique to solve hard problems as the one related with SCM. Taking into the above concerns, this section proposes decision support heuristics as given below in the table 1 for two echelon VMI systems considering the soft issues such as revenue sharing, pricing, real time communication, and determines the parameters such sales quantity, sales price and contract price between vendors and buyers for all two echelon environments.

\begin{tabular}{|c|c|c|}
\hline S.No & Environment & Proposed heuristics \\
\hline 1 & SV_SB & Iterative heuristic \\
\hline 2 & SV_MBO & SAA based heuristic \\
\hline 3 & MV_MBO & GA based heuristic \\
\hline
\end{tabular}

Table 1 Proposed heuristics

\subsection{Iterative heuristics for SV_SB problem}

Gjerdrum et al. (2002) addressed a method to fix fair transfer (contract) price in two enterprises SC and proposed an approach by applying the Nash bargaining principle for finding optimal multi-partner profit levels subject to given minimum echelon profit requirement. Fixation of contract price for the different revenue ratio is a tedious process, which leads to conflicts between partners, if it is not properly adopted in VMI system. Dong $\& \mathrm{Xu}$ (2002) represented cost functions of VMI in partial differential equation and proposed a methodology to determine optimal sales quantity without giving due consideration to contract price under different revenue shares and highlighted the benefits of VMI than that of traditional mode of operation. In order to mitigate the above limitation, a new methodology is required to determine the contract prices for known revenue shares between vendor and buyer with the objective of maximizing the channel profit in two-echelon SC operating under VMI mode. The procedure should be simple and it can be easily adapted in real time by SC managers (Achabal et. al., 2000). On this concern, this chapter proposes an iterative heuristic to find optimal contract and sales prices to operate under VMI mode for the problem described in section 4.1. Though the iterative approach involves large computations, present day computers can solve them within the reasonable time. Besides this, the time factor is not much crucial to this type of offline problems.

The proposed iterative heuristic involves the following two modules:

- Module 1: Determination of fair contract price $(W)$ for various demands $(y)$ or Sales prices $(P(y))$ on the assumption that they operate independently (i.e in Non VMI mode) with fair rewards or acceptable revenue shares.

- Module 2: Selection of optimal contract price $\left(W_{\text {opt }}\right)$ based on the channel profits in VMI mode from various acceptable contract price $(W)$ obtained in module 1.

Figure 8 illustrates the mechanism of the proposed iterative heuristic. 


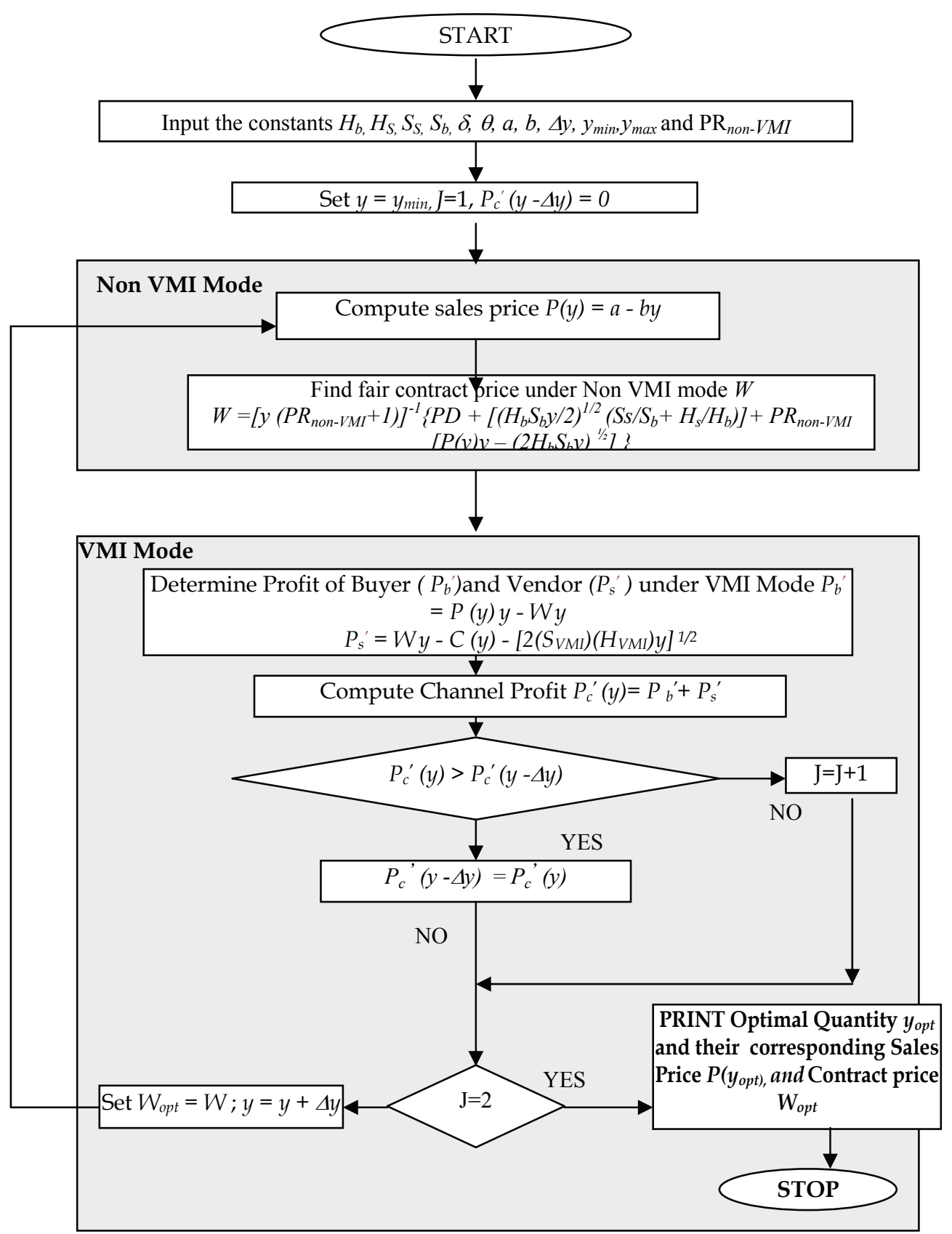

Figure 8. Iterative procedure of the proposed heuristic 


\subsection{SAA Based heuristics for SV_MBO}

Simulated annealing is also an intriguing technique for optimizing functions of many variables (Kirkpatrick et al., 1983). It is a heuristic strategy that provides a means for optimization of MINP problems those for which an exponentially increasing number of steps are required to generate an exact answer (Eglese, 1990). Simulated annealing is based on an analogy to the cooling of heated metals. Ponnambalam et al. (1999) states that the algorithm based on SAA, is a generalization of the well-known iterative improvement approach to combinatorial optimization problems. A generic procedure of SAA is given below in figure 9. The various steps involved in the proposed algorithm are explained below.

\subsubsection{Input module}

Table 2 and Table 3 serve as the input data sets to SV_MB problem. They are given as input in this module.

\begin{tabular}{|c|c|c|c|c|c|c|c|}
\hline \multirow{2}{*}{ Parameters } & \multicolumn{7}{|c|}{ Buyer } \\
\cline { 2 - 8 } & 1 & 2 & 3 & $\ldots$ & $j$ & $\ldots$ & $n$ \\
\hline Holding cost & $H_{b 1}$ & $H_{b 2}$ & $H_{b 3}$ & $\ldots$ & $H_{b j}$ & $\ldots$ & $H_{b n}$ \\
\hline Order / Setup Cost & $S_{b 1}$ & $S_{b 2}$ & $S_{b 3}$ & $\ldots$ & $S_{b j}$ & $\ldots$ & $S_{b n}$ \\
\hline Intercept & $a_{1}$ & $a_{2}$ & $a_{3}$ & $\ldots$ & $a_{j}$ & $\ldots$ & $a_{n}$ \\
\hline Cost slope & $b_{1}$ & $b_{2}$ & $b_{3}$ & $\ldots$ & $b_{j}$ & $\ldots$ & $b_{n}$ \\
\hline Minimum sales quantity & $y_{1 \min }$ & $y_{2 \min }$ & $y_{3 \min }$ & $\ldots$ & $y_{j \min }$ & $\ldots$ & $y_{n \min }$ \\
\hline Maximum sales quantity & $y_{1 \max }$ & $y_{2 \max }$ & $y_{3 \max }$ & & $y_{j \max }$ & $\ldots$ & $y_{n \max }$ \\
\hline Revenue Share Ratio & $P R_{1}$ & $P R_{2}$ & $P R_{3}$ & $\ldots$ & $P R_{j}$ & $\ldots$ & $P R_{n}$ \\
\hline Flow cost per unit & $\theta_{1}$ & $\theta_{2}$ & $\theta_{3}$ & $\ldots$ & $\theta_{j}$ & $\ldots$. & $\theta_{n}$ \\
\hline
\end{tabular}

Table 2. Buyer related data

\begin{tabular}{|c|c|c|c|c|}
\hline $\begin{array}{c}\text { Holding } \\
\text { cost }\end{array}$ & $\begin{array}{c}\text { Order / Setup } \\
\text { Cost }\end{array}$ & Capacity & $\begin{array}{c}\text { Production Cost per } \\
\text { unit. }\end{array}$ & $\begin{array}{c}\text { Outsourcing cost } \\
\text { constant }\end{array}$ \\
\hline$H_{S}$ & $S_{S}$ & $C$ & $\delta$ & $\eta$ \\
\hline
\end{tabular}

Table 3. Vendor related data

\subsubsection{Initialization module}

Choose an initial temperature, $T$. The value of $T$ is decided based upon the number of iterations to be performed. Here value of $T$ is taken as 450 (Eglese, 1990). An initial set of sales quantity of all buyers is generated randomly with binary representation. A set of 9 digit binary numbers addresses one buyer. Each seed solution comprising of ' $n$ ' buyers is decoded to provide the feasible sales quantity ' $y_{j}$ ' in integers by interpolating the seed information of the binary form with the following guidelines: Zero in all the nine digits would correspond to $y_{\text {jmin }}$ (i.e. $000000000 \Rightarrow y_{j \min }$ ) and 'one' in all the nine digits would correspond to $y_{\text {jmax }}$ (i.e. $111111111 \Rightarrow y_{\text {jmax }}$ ). The binary type representation and the physical meaning are as shown in figure 10. 


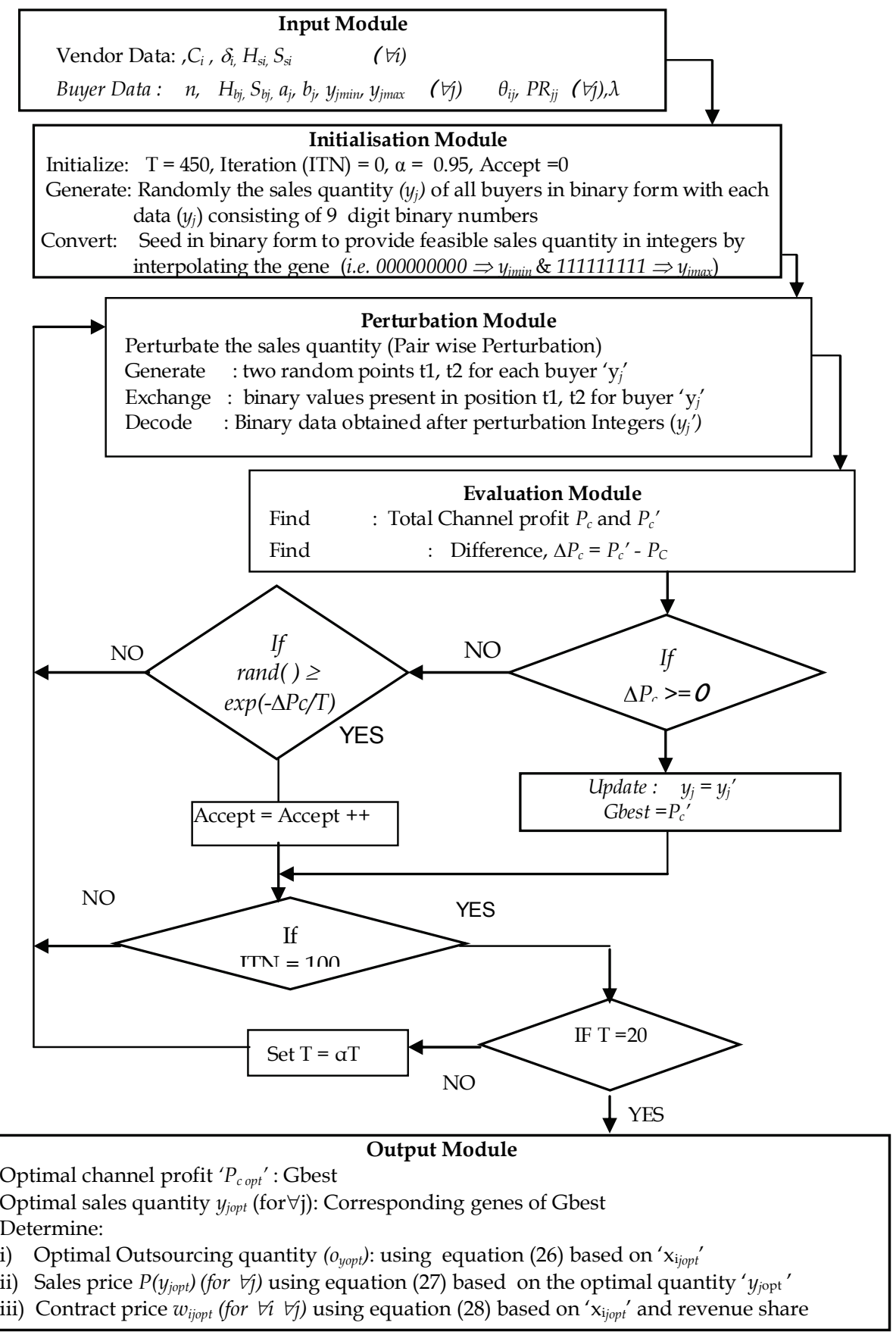

Figure 9. Flow chart representation of Simulated Annealing Algorithm process 


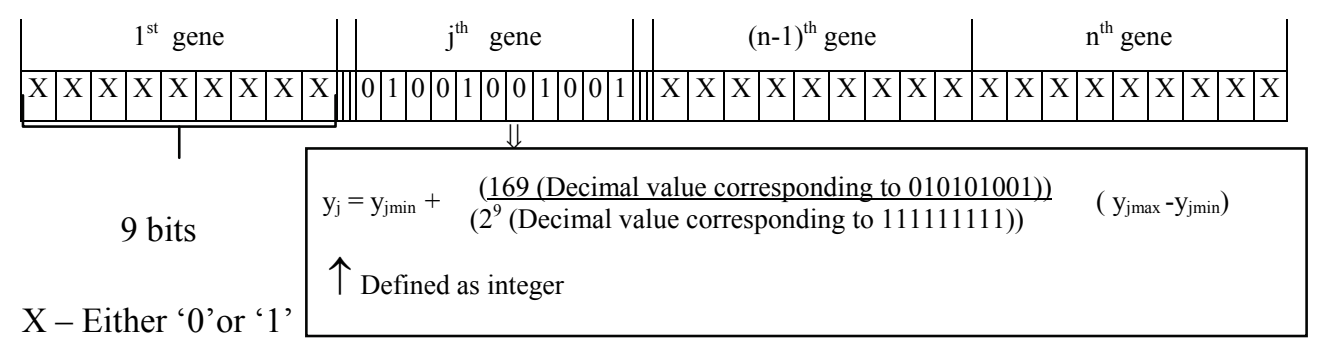

Figure 10. Binary representation and meaning

\subsubsection{Perturbation module}

Generate a feasible neighbour $y_{j}^{\prime}$ in the neighbourhood region of $y_{j}$ by using perturbation mechanism. Pair wise exchange perturbation scheme is used. Two points are randomly generated for all buyers and the binary digits corresponding to the two points are exchanged to obtain the new seed. Then they are decoded as above to obtain the feasible sales quantity $y_{j}^{\prime}$ in integers.

\subsubsection{Evaluation module}

In this module, the sales quantities of all buyers are decoded as above to obtain the feasible sales quantity $\left(y_{j}^{\prime}\right)$ in integers and the total channel profit are determined based on the following steps.

\section{Determination of total channel profit:}

The total channel profit $\left(\mathrm{P}_{\mathrm{c}}\right) \&\left(\mathrm{P}_{\mathrm{c}}{ }^{\prime}\right)$ is determined for the sales quantity $y_{j}$ and $y_{j}{ }^{\prime}$ respectively. Then the differences between the two channel profits are determined.

$$
\Delta \mathrm{Pc}_{\mathrm{C}}=\mathrm{Pc}^{\prime}-\mathrm{Pc}
$$

\subsubsection{Update module}

If the difference $\Delta P_{c}>=0$, accept the neighbour $y_{j}^{\prime}$ as seed, assign $\left(P_{c}{ }^{\prime}\right)$ as Gbest else accept the inferior neighbour as seed with probability ' $p$ '. i.e., rand ()$\leq \exp \left(-\Delta P_{c} / \mathrm{T}\right)$.

\subsubsection{Termination module}

Termination criterion is first checked to know whether the pre-determined number of iterations is completed. If it is not completed, it goes to perturbation module otherwise the initial temperature is multiplied by factor a to obtain the new temperature, and proceeds to next step. Here value of $a=0.95$ (Ponnambalam et al., 1999). A check is considered to identify whether the value of temperature falls below a predetermined value. If the value falls below then proceed to output module otherwise go to perturbation module. 


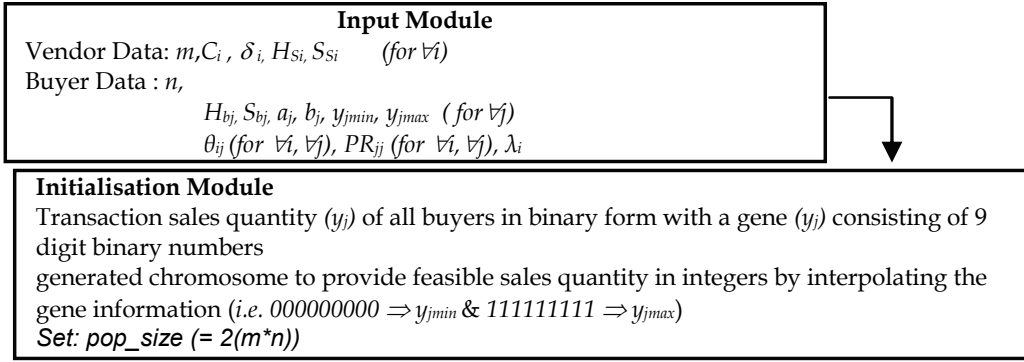

Decode: chromosome for ' $y_{j}$ ' $(j=1$ to $n)$

Allocation: Transaction quantity $\left(x_{i j}\right)$ between vendor ' $i$ ' and buyer ' $j$ ' based on vendor capacity and buyer sales quantity ' $y_{j}$ ' using north west corner rule

\begin{tabular}{|c|c|}
\hline \multicolumn{2}{|c|}{$\begin{array}{l}\text { Find: } \quad \text { fitness parameter i.e. ' } f(t)(c)^{\prime}={ }^{\prime} P_{c}^{\prime} \\
\text { Convert: ' } f(t)(c)^{\prime} \text { to new fitness value suitable for maximization objective }\end{array}$} \\
\hline $\begin{array}{ll}\text { Sorting } \\
\text { Sort: } & \text { Maximum ' fit }(c) \text { ' of each popu } \\
\text { Store: } & \text { Maximum ' fit }(c) \text { ' after all iterat }\end{array}$ & $\begin{array}{l}\text { le } \\
\text { nd assign it as local best } \\
\text { Gbest }\end{array}$ \\
\hline $\mathrm{NO}$ & YES \\
\hline New population generation module & Output Module \\
\hline 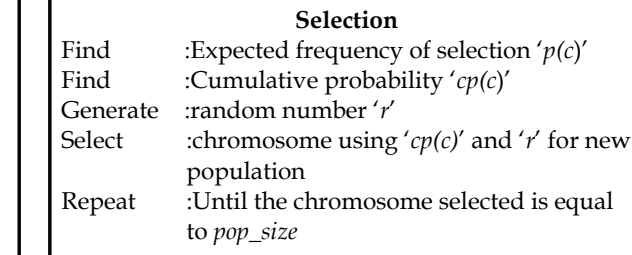 & $\begin{array}{l}\text { Optimal channel profit } P_{\text {copt }} \text { : Gbest } \\
\text { Optimal transaction quantity } x_{\text {ijopt }} \\
\text { (for } \forall i \forall j) \text { : Corresponding genes } \mathrm{f} \\
\text { Gbest } \\
\text { Determine: } \\
\text { i) Optimal outsourcing transaction } \\
\quad \text { quantity 'Ox } x_{i j o p t} \text { ' using equation }\end{array}$ \\
\hline 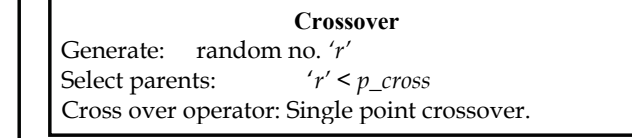 & $\begin{array}{l}\text { ii) Sales price } P\left(y_{j o p t}\right)(\text { for } \forall j) \text { using } \\
\text { equation (39) based on the optimal } \\
\text { quantity ' } x_{\text {ijopt }} \text { ' }\end{array}$ \\
\hline $\begin{array}{l}\text { Mutation } \\
\text { Generate: random no. ' } r \text { ' } \\
\text { Select: } \quad \text { genes having ' } r \text { ' }<p \_m u t \\
\text { Mutate: genes by replacing 'ONE' to 'ZERO' }\end{array}$ & $\begin{array}{l}\text { iii) Contract price } w_{i j o p t}(\text { for } \forall i \forall j) \text { using } \\
\text { equation }(40) \text { based on ' } \mathrm{x}_{\mathrm{ijopt}} \text { ' and } \\
\text { revenue share 'PR }{ }^{\prime}{ }^{\prime}\end{array}$ \\
\hline
\end{tabular}

Figure 11. Structure of proposed GA based heuristics 


\subsubsection{Output module}

After completion of all iterations, the Gbest fitness parameter sorted out is considered as the optimal channel profit $P_{\text {copt }}$ and its corresponding $y_{j}($ for $\forall j)$ becomes sales quantity of all the buyers $y_{\text {jopt }}($ for $\forall j)$. Optimal outsourcing quantity is determined using equation 26 . Next, the optimal sales price $P\left(y_{\text {jopt }}\right)$ (for $\forall j$ ) and optimal contract price $W_{\text {jopt }}($ for $\forall j)$ corresponding to the optimal quantity $y_{\text {jopt }}$ determined using the equations 27 and 28 respectively. Complete output obtained is shown in Table 4 for the optimal channel profit $P_{\text {copt }}$.

\begin{tabular}{|c|c|c|c|c|c|c|c|}
\hline Operating Parameters & Buyer 1 & Buyer 2 & Buyer 3 & $* * * *$ & Buyer j & $* * * *$ & Buyer $n$ \\
\hline Sales Quantity & $y_{1 o p t}$ & $y_{2 o p t}$ & $y_{3 o p t}$ & $* * * *$ & $y_{\text {jopt }}$ & $* * * *$ & $y_{\text {nopt }}$ \\
\hline Contract price & $W_{\text {lopt }}$ & $W_{2 o p t}$ & $W_{3 o p t}$ & $* * * *$ & $W_{\text {jopt }}$ & $* * * *$ & $W_{\text {nopt }}$ \\
\hline Sales price & $P\left(y_{1 o p t}\right)$ & $P\left(y_{2 o p t}\right)$ & $P\left(y_{3 o p t)}\right.$ & $* * * *$ & $P\left(y_{\text {jopt }}\right)$ & $* * * *$ & $P\left(y_{\text {nopt }}\right)$ \\
\hline $\begin{array}{c}\text { Optimal Outsourcing } \\
\text { quantity }\end{array}$ & \multicolumn{7}{|c|}{ 'o yopt' } \\
\hline
\end{tabular}

Table 4. Optimal operating parameters

\subsection{GA Based heuristics for MV_MBO}

The mathematical model formulated for the determination of ' $x_{i j o p t}$ ' (for $\forall i, \forall j$ ) to the MV_MBO belongs to Mixed Nonlinear Integer Programming (MNIP) problem. The objective function is nonlinear involving ' $n$ ' mixed integer variables and one linear constraint for sales quantity of buyers. The Hessian matrix of the objective function confirms the nature of it as non-convex (Ravindran et al., 2000). LINGO optimization solver can be used to solve such MNIP problem of smaller in size. Yokota et al. (1996) presented the usefulness of GA for MNIP problems to provide optimal or near optimal solutions. Costa \& Oliveira (2001) addressed that evolution strategies such as GA, SAA and ES are emerging as the best algorithm for MNIP problems. Mccall (2005) stated that one of the most attractive features of the GA is its flexibility on handling various objective functions with fewer requirements for fine mathematical properties. Taking into account the above concerns, GA based heuristics is proposed to evolve optimal or near optimal transaction quantity ' $x_{i j o p t}$ (for $\forall i, \forall j$ ) for maximum channel profit to the MV_MBO model. The optimal Outsourcing transaction quantity 'O $x_{i j o p t}$ ', optimal sales price $P\left(y_{j o p t}\right) \quad($ for $\forall j)$ and optimal contract price ' $W_{i j o p t}$ '(for $\left.\forall i, \forall j\right)$ are derived subsequently with the ' $x_{i j o p t}$ ' (for $\forall i, \forall j$ ) obtained through GA. Flow chart given in figure 11. outlines the structure of the various modules of the proposed GA based heuristic and are explained briefly in this section .

\subsubsection{Input module}

Table 5 -7 shows the input data sets of MV_MBO problem. They are given as input in this module. 


\begin{tabular}{|c|c|c|c|c|c|c|c|}
\hline \multirow{2}{*}{ Parameters } & \multicolumn{7}{|c|}{ Buyer } \\
\cline { 2 - 8 } & 1 & 2 & 3 & $\ldots$ & $j$ & $\ldots$. & $n$ \\
\hline Holding cost & $H_{b 1}$ & $H_{b 2}$ & $H_{b 3}$ & $\ldots$ & $H_{b j}$ & $\ldots$ & $H_{b n}$ \\
\hline Order / Setup Cost & $S_{b 1}$ & $S_{b 2}$ & $S_{b 3}$ & $\ldots$ & $S_{b j}$ & $\ldots$ & $S_{b n}$ \\
\hline Intercept & $a_{1}$ & $a_{2}$ & $a_{3}$ & $\ldots$ & $a_{j}$ & $\ldots$ & $a_{j n}$ \\
\hline Cost slope & $b_{1}$ & $b_{2}$ & $b_{3}$ & $\ldots$ & $b_{j}$ & $\ldots$ & $b_{n}$ \\
\hline Minimum sales quantity & $y_{1 \min }$ & $y_{2 \min }$ & $y_{3 \min }$ & $\ldots$ & $y_{j \min }$ & $\ldots$ & $y_{n \min }$ \\
\hline Maximum sales quantity & $y_{1 \max }$ & $y_{2 \max }$ & $y_{3 \max }$ & & $y_{j \max }$ & $\ldots$ & $y_{n \max }$ \\
\hline
\end{tabular}

Table 5. Buyer related data

\begin{tabular}{|c|c|c|c|c|c|c|c|}
\hline \multirow{2}{*}{ Parameters } & \multicolumn{7}{|c|}{ Vendor } \\
\cline { 2 - 8 } & 1 & 2 & 3 & $\ldots$ & $i$ & $\ldots$ & $m$ \\
\hline Holding cost & $H_{S 1}$ & $H_{S 2}$ & $H_{S 3}$ & $\ldots$ & $H_{S j}$ & $\ldots$ & $H_{S m}$ \\
\hline Order / Setup Cost & $S_{S 1}$ & $S_{S 2}$ & $S_{S 3}$ & $\ldots$ & $S_{S j}$ & $\ldots$ & $S_{S n m}$ \\
\hline Capacity & $C_{1}$ & $C_{2}$ & $C_{3}$ & $\ldots$ & $C_{i}$ & $\ldots$ & $C_{m}$ \\
\hline Production cost per unit & $\delta_{1}$ & $\delta_{2}$ & $\delta_{3}$ & $\ldots$ & $\delta_{i}$ & & $\delta_{m}$ \\
\hline Outsourcing cost parameter & $\lambda_{1}$ & $\lambda_{2}$ & $\lambda_{3}$ & $\ldots$ & $\lambda_{i}$ & $\ldots$ & $\lambda_{m}$ \\
\hline
\end{tabular}

Table 6. Vendor related data

\begin{tabular}{|c|c|c|c|c|c|c|c|c|}
\hline \multirow{2}{*}{ Parameters } & \multirow{2}{*}{ Vendor } & \multicolumn{7}{|c|}{ Buyer } \\
\hline & & 1 & 2 & 3 & $\ldots$ & $j$ & $\ldots$ & $n$ \\
\hline \multirow{3}{*}{ Revenue Share Ratio } & 1 & $P R_{11}$ & $P R_{12}$ & $P R_{13}$ & $\ldots$ & $P R_{1 j}$ & $\ldots$ & $P R_{1 n}$ \\
\hline & $i$ & $P R_{i 1}$ & $P R_{i 2}$ & $P R_{i 3}$ & $\ldots$ & $P R_{i j}$ & $\ldots$ & $P R_{\text {in }}$ \\
\hline & $m$ & $P R_{m 1}$ & $P R_{m 2}$ & $P R_{m 3}$ & $\ldots$ & $P_{m j}$ & $\ldots$ & $P R_{m n}$ \\
\hline \multirow{3}{*}{ Flow cost per unit } & 1 & $\theta_{11}$ & $\theta_{12}$ & $\theta_{13}$ & $\ldots$ & $\theta_{1 j}$ & $\ldots$ & $\theta_{1 n}$ \\
\hline & $i$ & $\theta_{i 1}$ & $\theta_{i 2}$ & $\theta_{i 3}$ & $\ldots$ & $\theta_{i j}$ & $\ldots$ & $\theta_{i n}$ \\
\hline & $m$ & $\theta_{m 1}$ & $\theta_{m 2}$ & $\theta_{m 3}$ & $\ldots$ & $\theta_{m j}$ & $\ldots$ & $\theta_{m n}$ \\
\hline
\end{tabular}

Table 7. Common data between vendor and buyer

\subsubsection{Initialization module}

This module generates the chromosomes of initial population. Each chromosome ' $c$ ' represents the randomly generated sales quantities of all buyers with the $j^{\text {th }}$ gene indicating the sales quantity ' $y_{j}$ ' of buyer ' $j$ '. The procedure for initialisation of random sales quantity of all buyers is similar to the one expressed in section 5.2.2.

The size of the population depends on the feasible solution space of the problem, which is normally dependent on the number of decision variables (Michalewicz, 1994). Under this consideration, the population size (pop_size) is set as the twice the number of buyers (i.e. pop_size $=2 \mathrm{n})$. 


\subsubsection{Allocation module}

In this module, the transaction quantities are allocated between the vendors and the buyers basing on the following steps

i. Decoding of chromosomes: The chromosome ' $c$ ' is decoded to provide feasible sales quantity $\left(y_{j}\right)($ for $\forall j)$

ii. Allocation of transaction quantity: Transaction quantity $\left(x_{i j}\right)$ are allocated between vendor ' $i$ ' and buyer ' $j$ ' based on vendor capacity $\left(C_{i}\right)$ and buyer sales quantity $\left(y_{j}\right)$ using north west corner rule.

\subsubsection{Evaluation module}

In this module, the population is evaluated and the probability of selection of each chromosome is found out. Maximisation of channel profit $P_{c}{ }^{\prime}$ is considered as an evaluation criterion. Each and every chromosome is tested for its fitness based on the following steps given below for the next generation.

i. Determination of fitness parameter value: The fitness parameter ' $f i t(c)$ ' is the channel profit $P_{c}$ and is calculated using equation (35) for chromosome ' $c$ ' by substituting the feasible sales quantities ' $y_{j}$ '

ii. Conversion of fitness parameter value to new fitness parameter value: This step converts the fitness parameter to a new fitness value 'newfit(c)' suitable for the maximization objective and scaling them high, so that a very few extremely superior individuals would be selected as parents too many times. Selecting the best conversion function can be some what problem dependant. However, one function that has been found to generally useful is the exponential (Masters, 1993).

i.e.,

$$
\text { new fit(c) }=\mathrm{e}^{\mathrm{kfit}(\mathrm{c})}
$$

Where $\mathrm{k}$ is constant and the value of the constant is usually set by trails in order to scale the fitness function reasonably to retain at least half of the good chromosomes in the population find place in the new population. Hence the new fitness parameter value is set as:

$$
\text { new fit }(\mathrm{c})=\mathrm{e}^{0.0005 \mathrm{fit}(\mathrm{C}}
$$

iii. Conversion of new fitness to an expected frequency of selection: The final evaluation step is to convert the new fitness parameter to an expected frequency / probability of selection $(p(c))$ of chromosome ' $c$ ' by the sum of the new fitness values of all chromosomes.

$$
\text { i.e., } \quad \mathrm{p}(\mathrm{c})=\text { new fit }(\mathrm{c}) / \sum_{c=1}^{c=p o p_{-}} \text {size } n e w f i t(c)
$$

\subsubsection{Sorting module}

In this module, the maximum fitness parameter is sorted out for each population and it will be stored as the local best. The maximum value is sorted out after all iterations and it is stored as the Global best.

\subsubsection{Termination criterion}

Termination criterion is checked after sorting module to know whether the pre-determined number of iterations is completed. On its completion, the algorithm passes to the output 
module, otherwise, the new set of population is generated as given in the new population generation module. The number of generations (iterations) depends upon the nature and size of the problem and is fixed by user.

\subsubsection{New population generation module}

Selection of next population is based on survival probability, crossover to produce children and mutation to induce external influence in new generation.

\subsubsection{Selection module}

The next population of the same size is obtained with random selection with the help of a roulette wheel procedure of which is explained here below. First the cumulative probabilities of selection / survival ' $c p(c)$ ' of all the chromosomes are found out.

$$
\text { i.e., } \quad \mathrm{cp}(\mathrm{c})=\sum_{c=1}^{c=c} \mathrm{p}(\mathrm{c})
$$

Then the random number ' $r$ ' between 0 and 1 is generated and a chromosome ' $c$ ' is selected, satisfying the following condition:

$$
\mathrm{cp}(\mathrm{c}) \geq \mathrm{r}>\mathrm{cp}(\mathrm{c}-1)
$$

This selection process is repeated as many times as equal to population size. This method used here is more reliable because, it guarantees that most fit individuals will be selected, and that the actual number of times each chromosome selected will be within one of its expected frequency. This procedure enables fit chromosome to get multiple copies and the worst chromosome to die off.

\subsubsection{Crossover module}

This involves two steps, viz., (i) selection of chromosome for crossover and (ii) cross over operation. Probability of crossover ' $p \_$cross' is a vital parameter in cross over operation. The value for $p_{-}$cross is assumed as 0.6 so that atleast $60 \%$ of chromosomes selected in the earlier selection module will undergo crossover operation and produce offspring. The procedure for this selection is as follows: Random numbers between 0 and 1 are generated for all chromosomes, and those chromosomes with random numbers less than $p_{-}$cross value are the chromosomes selected for crossover. If the number of selected chromosomes is odd, then the above procedure is repeated until one more chromosomes get selected and the number of selected chromosomes becomes an even number.

The next step is to carry the crossover operation, a reproduction method. There are so many cross operations (Michalewicz, 1994). This work uses simple single point cross over. In which a cutting point is introduced at random, which splits the selected chromosomes into two parts into left and right. The right parts of the parent chromosomes are swapped to produce two new off springs. This process is continued for all the chromosomes selected for crossover.

\subsubsection{Mutation module}

The purpose of mutation is the introduction of new genetic material, or the recreation of good genes that were lost by chance through poor selection of mates. To do this effectively, 
the effect of mutation must be profound. At the same time, the valuable gene pool must be protected from wanton destruction. Thus, the probability of mutation ' $p \_m u t^{\prime}$ ' should be tiny (Masters, 1993). On the above grounds, the value of ' $p \_m u t^{\prime}$ ' is assumed as 0.03 in this chapter. The procedure followed for mutation is as follows: Random number is generated for each gene in the population; the genes that get random number ' $r$ ' less than ' $p_{-} m u t^{\text {' }}$ undergo mutation; the selected genes are mutated by replacing 'ONE' to 'ZERO' and vice versa.

\subsubsection{Output pricing module}

After completion of all iterations, the 'global best' fitness parameter sorted out is considered as the optimal channel profit ' $P_{\text {copt }}$ ' and its corresponding optimal sales quantity of all buyers is ' $y_{\text {jopt }}$ '. This module derives the optimal sales price ' $P\left(y_{\text {jopt }}\right)$ ' and acceptable contract price ' $W_{\text {jopt }}$ ' for the optimal quantity ' $y_{\text {jopt }}$ ' determined from the previous module. Sales price for each buyer is calculated using the equation (39) and contact price for each buyer is calculated using equation (40). Complete output obtained is shown in Table 8 for the optimal channel profit ' $P_{\text {copt }}$.

\begin{tabular}{|c|c|c|c|c|c|c|c|c|c|c|}
\hline \multirow{3}{*}{\multicolumn{2}{|c|}{$\begin{array}{l}\text { Operating } \\
\text { Parameters }\end{array}$}} & \multicolumn{9}{|c|}{ Buyer } \\
\hline & & \multicolumn{3}{|c|}{1} & \multicolumn{3}{|c|}{$j$} & \multicolumn{3}{|c|}{$n$} \\
\hline & & $x_{i j}$ & $O x_{i j}$ & $W_{i j}$ & $x_{i j}$ & $O x_{i j}$ & $W_{i j}$ & $x_{i j}$ & $O x_{i j}$ & $W_{i j}$ \\
\hline \multirow{3}{*}{ Supplier } & 1 & $x_{11 \text { opt }}$ & $O x_{11 \text { opt }}$ & $W_{11 o p t}$ & $x_{1 \text { jopt }}$ & $O x_{1 j o p t}$ & $W_{1 \text { jopt }}$ & $X_{\text {1nopt }}$ & $O x_{1 \text { nopt }}$ & $W_{\text {1nopt }}$ \\
\hline & $i$ & $x_{\text {i1opt }}$ & $O x_{\text {ilopt }}$ & $W_{\text {ilopt }}$ & $x_{i j o p t}$ & $O x_{i j o p t}$ & $W_{i j o p t}$ & $x_{\text {inopt }}$ & $O x_{\text {inopt }}$ & $W_{\text {inopt }}$ \\
\hline & $m$ & $x_{\text {m1opt }}$ & $O x_{\text {m1opt }}$ & $W_{\text {m1opt }}$ & $x_{\text {mjopt }}$ & $O x_{\text {mjopt }}$ & $W_{\text {mjopt }}$ & $x_{\text {mnopt }}$ & $O x_{\text {mnopt }}$ & $W_{\text {mnopt }}$ \\
\hline \multicolumn{2}{|c|}{ Demand } & \multicolumn{3}{|c|}{$y_{1}$} & \multicolumn{3}{|c|}{$y_{j}$} & \multicolumn{3}{|c|}{$y_{m n}$} \\
\hline \multicolumn{2}{|c|}{ Sales price } & \multicolumn{3}{|c|}{$P\left(y_{1 \text { lopt }}\right)$} & \multicolumn{3}{|c|}{$P\left(y_{\text {jopt }}\right)$} & \multicolumn{3}{|c|}{$P\left(y_{\text {nopt }}\right)$} \\
\hline \multicolumn{2}{|c|}{$\begin{array}{c}\text { Channel } \\
\text { profit }\end{array}$} & \multicolumn{9}{|c|}{$P_{\text {copt }}$} \\
\hline
\end{tabular}

Table 8. Optimal operating parameters

\section{Illustration}

This section illustrates the GA based heuristic proposed for MV_MBO model with a pilot study data from agricultural development offices situated at three rural places of south India. The landowners (vendor) supply rice grains to these agricultural development offices. The agricultural development offices (buyers) supply their products (rice grains) to the customers. This section illustrates the proposed methodology only with 2 vendors and three buyers and it can as well be extended, to ' $m$ ' vendors and ' $n$ ' buyers. The vendor is currently operating in independent mode where the buyers initiate the orders everyday. Based on the orders, the vendors supply the required quantities to buyers. Table 9, 10 and 11 provide the buyer related data, vendor related data and the common data between vendor and buyers respectively. 


\begin{tabular}{|c|c|c|c|}
\hline $\mathrm{y}_{\mathrm{j}}$ & $\mathbf{1}$ & $\mathbf{2}$ & $\mathbf{3}$ \\
\hline $\mathrm{H}_{\mathrm{bj}}$ & 2 & 1 & 2 \\
\hline $\mathrm{S}_{\mathrm{bj}}$ & 5 & 5 & 7 \\
\hline $\mathrm{a}_{\mathrm{j}}$ & 23 & 22 & 21 \\
\hline $\mathrm{b}_{\mathrm{j}}$ & 0.0001 & 0.0002 & 0.0003 \\
\hline $\mathrm{y}_{\text {jmin }}$ & 1000 & 2000 & 1000 \\
\hline $\mathrm{y}_{\mathrm{jmax}}$ & 2000 & 3000 & 3000 \\
\hline
\end{tabular}

Table 9. Buyer related data

\begin{tabular}{|c|c|c|c|c|c|}
\hline $\mathrm{i}$ & $\mathrm{H}_{\mathrm{si}}$ & $\mathrm{S}_{\mathrm{si}}$ & $\mathrm{C}_{\mathrm{i}}$ & $\delta_{\mathrm{i}}$ & $\lambda_{\mathrm{i}}$ \\
\hline $\mathbf{1}$ & 2 & 10 & 3000 & 15 & 0.2 \\
\hline $\mathbf{2}$ & 1 & 9 & 3000 & 16 & 0.2 \\
\hline
\end{tabular}

Table 10. Vendor related data

\begin{tabular}{|c|c|c|c|c|}
\hline \multirow{2}{*}{ Parameters } & \multirow{2}{*}{} & \multicolumn{3}{|c|}{$j$} \\
\cline { 3 - 5 } & \multirow{2}{*}{$I$} & $\mathbf{1}$ & $\mathbf{2}$ & $\mathbf{3}$ \\
\hline \multirow{2}{*}{$P R_{i j}$} & 1 & 1.2 & 1.1 & 1.3 \\
\hline \multirow{2}{*}{$\theta_{i j}$} & 2 & 1.2 & 1.2 & 1.1 \\
\hline & 1 & 0.004 & 0.002 & 0.005 \\
\cline { 2 - 5 } & 2 & 0.005 & 0.003 & 0.002 \\
\hline
\end{tabular}

Table 11. Common data between vendor and buyer

Various modules of the GA heuristic are shown in Tables 12 to 19 respectively, and the optimal parameters for the case problem are shown in Tables 20. The GA parameters used are as follows: chromosome length $=27$, pop_size $=12, p \_$cross $=0.6, p \_$mut $=0.03$, number of iterations $=100$.

\begin{tabular}{|c|c|c|c|c|c|c|c|c|c|c|c|c|c|c|c|c|c|c|c|c|c|c|c|c|c|c|c|}
\hline 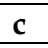 & \multicolumn{27}{|c|}{ Chromosomes } \\
\hline 1 & 1 & & 0 & 0 & 0 & 0 & 0 & 1 & 0 & 1 & 1 & 1 & 0 & 1 & 0 & 1 & 1 & 0 & 0 & 1 & 1 & 1 & 0 & 1 & 0 & 0 & \\
\hline 2 & 0 & & 1 & 0 & 1 & 0 & 1 & 1 & 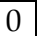 & 0 & 1 & 0 & & & 4 & 7 & 1 & 1 & 0 & 0 & 1 & 0 & 1 & 0 & 1 & 1 & \\
\hline 3 & 1 & & 0 & 1 & 0 & 1 & 1 & 1 & 0 & 1 & 1 & 0 & & 1 & 0 & 0 & 1 & 1 & 1 & 0 & 1 & 1 & 1 & 1 & 0 & 0 & \\
\hline 4 & 1 & & 1 & 1 & 1 & 0 & 1 & 1 & 1 & 0 & 1 & 1 & 1 & 1 & 1 & 1 & 0 & \begin{tabular}{|l|}
0 \\
\end{tabular} & 1 & 1 & 0 & 0 & 1 & 0 & 0 & 1 & \\
\hline 5 & 1 & & 1 & 0 & 1 & 1 & 0 & 0 & 0 & U & & 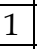 & 0 & & & 7 & 1 & 0 & 0 & 0 & 0 & 1 & 0 & 1 & 1 & 1 & \\
\hline 6 & 1 & & 0 & 0 & 0 & 0 & 1 & 0 & 1 & 0 & 0 & 1 & & & & 1 & 1 & 1 & 1 & 0 & 1 & 1 & 0 & 1 & 1 & 1 & \\
\hline 7 & 0 & & 1 & 1 & 0 & 0 & 1 & 0 & 0 & 0 & 0 & 0 & & & & 0 & 0 & 1 & 1 & 1 & 0 & 0 & 1 & 0 & 0 & 0 & \\
\hline 8 & 1 & 1 & 0 & 1 & 0 & 1 & 0 & 1 & 0 & 1 & 1 & 0 & & 1 & 1 & 0 & 1 & 0 & 1 & 1 & 0 & 1 & 1 & 0 & 1 & 1 & \\
\hline 9 & 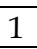 & & 1 & 1 & 0 & 1 & 0 & 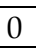 & 1 & 1 & 0 & 1 & & 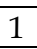 & 0 & - & 0 & 1 & 0 & 0 & 0 & 0 & 0 & 1 & 1 & \begin{tabular}{|l|l|}
0 \\
\end{tabular} & \\
\hline 10 & 1 & & 1 & 0 & 1 & 1 & 1 & 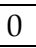 & 0 & 0 & 0 & 1 & & 0 & 1 & 0 & 1 & 0 & 1 & 1 & 0 & 1 & 1 & 0 & 1 & 1 & 0 \\
\hline 11 & 0 & & 1 & 0 & 1 & 1 & 0 & 1 & 0 & 1 & 0 & 0 & & U & 1 & 1 & 0 & 0 & 1 & 0 & 0 & 1 & 1 & 0 & 0 & 0 & \\
\hline 12 & 0 & & 0 & 1 & 1 & 0 & 0 & 1 & 1 & 1 & 0 & 1 & 1 & 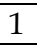 & 1 & 0 & 0 & 0 & 1 & 1 & 0 & 0 & 1 & 0 & 1 & \begin{tabular}{|l|}
0 \\
\end{tabular} & \\
\hline
\end{tabular}

Table 12. Initial population of chromosomes 


\begin{tabular}{|c|c|c|c|c|c|c|}
\hline \multirow{2}{*}{$\mathrm{c}$} & \multicolumn{3}{|c|}{$\mathrm{yj}_{\mathrm{j}}$} & \multirow{2}{*}{ fit(c) } & newfit (c) & \multirow{2}{*}{$\mathrm{P}(\mathrm{c})$} \\
\cline { 2 - 4 } & 1 & 2 & 3 & & 32621.34 & 0.056 \\
\hline 1 & 1504 & 2919 & 1911 & 22527.23 & 45517.29 & 0.079 \\
\hline 2 & $\mathbf{1 1 6 8}$ & $\mathbf{2 3 7 3}$ & $\mathbf{1 3 3 6}$ & $\mathbf{2 3 0 7 3 . 6 3 ^ { * }}$ & 53400.18 & 0.092 \\
\hline 3 & 1841 & 2788 & 2475 & 22706.20 & 45697.27 & 0.079 \\
\hline 4 & 1984 & 2493 & 2577 & 22150.13 & 51181.93 & 0.088 \\
\hline 5 & 1923 & 2183 & 1183 & 22398.5 & 58623.6 & 0.101 \\
\hline 6 & 1761 & 2185 & 2432 & 2222.8 & 72326.35 & 0.125 \\
\hline 7 & 1446 & 2111 & 2565 & 21979.21 & 30547.52 & 0.053 \\
\hline 8 & 1833 & 2864 & 2714 & 21989.09 & 65408.42 & 0.113 \\
\hline 9 & 1956 & 2722 & 1046 & 21627.15 & 50323.69 & 0.087 \\
\hline 10 & 1931 & 2144 & 2714 & 21098.45 & 16496.19 & 0.028 \\
\hline 11 & 1426 & 2524 & 2189 & 21765.37 & 53027.41 & 0.092 \\
\hline 12 & 1350 & 2735 & 2585 & 21542.8 & & \\
\hline
\end{tabular}

*Local Best

Table 13. Parameters for the generation of new population

\begin{tabular}{|c|c|c|c|}
\hline $\mathrm{c}$ & $\mathrm{cp}(\mathrm{c})$ & $\mathrm{R}$ & Selected \\
\hline 1 & 0.056 & 0.21 & $1^{\prime}(9)$ \\
\hline 2 & 0.135 & 0.03 & $2^{\prime}(3)$ \\
\hline 3 & 0.228 & 0.21 & $3^{\prime}(3)$ \\
\hline 4 & 0.308 & 0.97 & $4^{\prime}(7)$ \\
\hline 5 & 0.397 & 0.91 & $5^{\prime}(9)$ \\
\hline 6 & 0.499 & 0.66 & $6^{\prime}(3)$ \\
\hline 7 & 0.624 & 0.51 & $7^{\prime}(7)$ \\
\hline $8 \mathrm{~s}$ & 0.677 & 0.11 & $8^{\prime}(7)$ \\
\hline 9 & 0.791 & 0.78 & $9^{\prime}(9)$ \\
\hline 10 & 0.879 & 0.9 & $10^{\prime}(9)$ \\
\hline 11 & 0.907 & 0.28 & $11^{\prime}(3)$ \\
\hline 12 & 1 & 0.9 & $12^{\prime}(7)$ \\
\hline
\end{tabular}

Table 14. New population before crossover and mutation

\begin{tabular}{|c|c|c|}
\hline $\mathrm{C}^{\prime}$ & $\mathrm{r}$ & $\mathrm{S} / \mathrm{NS}^{*}$ \\
\hline $1^{\prime}$ & 0.62 & $\mathrm{NS}$ \\
\hline $2^{\prime}$ & 0.44 & $\mathrm{~S}$ \\
\hline $3^{\prime}$ & 0.86 & $\mathrm{NS}$ \\
\hline $4^{\prime}$ & 0.79 & $\mathrm{NS}$ \\
\hline $5^{\prime}$ & 0.12 & $\mathrm{~S}$ \\
\hline $6^{\prime}$ & 0.99 & $\mathrm{NS}$ \\
\hline $7^{\prime}$ & 0.93 & $\mathrm{NS}$ \\
\hline $8^{\prime}$ & 0.24 & $\mathrm{~S}$ \\
\hline $9^{\prime}$ & 0.75 & $\mathrm{NS}$ \\
\hline $10^{\prime}$ & 0.71 & $\mathrm{NS}$ \\
\hline $11^{\prime}$ & 0.01 & $\mathrm{~S}$ \\
\hline $12^{\prime}$ & 0.91 & $\mathrm{NS}$ \\
\hline
\end{tabular}

*S: Selected / NS: Not Selected

Table 15. Selection of chromosome for crossover 


\begin{tabular}{|c|c|c|c|c|c|c|c|c|c|c|c|c|c|c|c|c|c|c|c|c|c|c|c|c|c|c|c|}
\hline $\mathbf{c}^{\prime}$ & \multicolumn{11}{|c|}{ Parents } \\
\hline $2^{\prime}$ & 0 & 0 & 1 & 0 & 1 & 0 & 1 & 1 & 0 & 0 & 1 & 0 & 1 & 1 & 1 & 1 & $\mathbf{1}$ & $\mathbf{1}$ & $\mathbf{0}$ & $\mathbf{0}$ & $\mathbf{1}$ & $\mathbf{0}$ & $\mathbf{1}$ & $\mathbf{0}$ & $\mathbf{1}$ & $\mathbf{1}$ & $\mathbf{0}$ \\
\hline $5^{\prime}$ & 1 & 1 & 1 & 0 & 1 & 1 & 0 & 0 & 0 & 0 & 0 & 1 & 0 & 1 & 1 & 1 & $\mathbf{1}$ & $\mathbf{0}$ & $\mathbf{0}$ & $\mathbf{0}$ & $\mathbf{0}$ & $\mathbf{1}$ & $\mathbf{0}$ & $\mathbf{1}$ & $\mathbf{1}$ & $\mathbf{1}$ & $\mathbf{1}$ \\
\hline $8^{\prime}$ & 1 & 1 & 0 & 1 & 0 & 1 & 0 & 1 & 0 & 1 & 1 & 0 & 1 & 1 & 1 & 0 & 1 & $\mathbf{0}$ & $\mathbf{1}$ & $\mathbf{1}$ & $\mathbf{0}$ & $\mathbf{1}$ & $\mathbf{1}$ & $\mathbf{0}$ & $\mathbf{1}$ & $\mathbf{1}$ & $\mathbf{0}$ \\
\hline $11^{\prime}$ & 0 & 1 & 1 & 0 & 1 & 1 & 0 & 1 & 0 & 1 & 0 & 0 & 0 & 0 & 1 & 1 & 0 & $\mathbf{0}$ & $\mathbf{1}$ & $\mathbf{0}$ & $\mathbf{0}$ & $\mathbf{1}$ & $\mathbf{1}$ & $\mathbf{0}$ & $\mathbf{0}$ & $\mathbf{0}$ & $\mathbf{0}$ \\
\hline
\end{tabular}

Table 16. Parents selected for cross over

\begin{tabular}{|c|c|c|c|c|c|c|c|c|c|c|c|c|c|c|c|c|c|c|c|c|c|c|c|c|c|c|c|}
\hline $\mathbf{c}^{\prime \prime}$ & \multicolumn{11}{|c|}{ Parents } \\
\hline $2^{\prime \prime}$ & 0 & 0 & 1 & 0 & 1 & 0 & 1 & 1 & 0 & 0 & 1 & 0 & 1 & 1 & 1 & 1 & $\mathbf{1}$ & $\mathbf{0}$ & $\mathbf{0}$ & $\mathbf{0}$ & $\mathbf{0}$ & $\mathbf{1}$ & $\mathbf{0}$ & $\mathbf{1}$ & $\mathbf{1}$ & $\mathbf{1}$ & $\mathbf{1}$ \\
\hline $5^{\prime \prime}$ & 1 & 1 & 1 & 0 & 1 & 1 & 0 & 0 & 0 & 0 & 0 & 1 & 0 & 1 & 1 & 1 & $\mathbf{1}$ & $\mathbf{1}$ & $\mathbf{0}$ & $\mathbf{0}$ & $\mathbf{1}$ & $\mathbf{0}$ & $\mathbf{1}$ & $\mathbf{0}$ & $\mathbf{1}$ & $\mathbf{1}$ & $\mathbf{0}$ \\
\hline $8^{\prime \prime}$ & 1 & 1 & 0 & 1 & 0 & 1 & 0 & 1 & 0 & 1 & 1 & 0 & 1 & 1 & 1 & 0 & 1 & $\mathbf{0}$ & $\mathbf{1}$ & $\mathbf{0}$ & $\mathbf{0}$ & $\mathbf{1}$ & $\mathbf{1}$ & $\mathbf{0}$ & $\mathbf{0}$ & $\mathbf{0}$ & $\mathbf{0}$ \\
\hline $11^{\prime \prime}$ & 0 & 1 & 1 & 0 & 1 & 1 & 0 & 1 & 0 & 1 & 0 & 0 & 0 & 0 & 1 & 1 & 0 & $\mathbf{0}$ & $\mathbf{1}$ & $\mathbf{1}$ & $\mathbf{0}$ & $\mathbf{1}$ & $\mathbf{1}$ & $\mathbf{0}$ & $\mathbf{1}$ & $\mathbf{1}$ & $\mathbf{0}$ \\
\hline
\end{tabular}

Table 17. Off springs of selected parents

\begin{tabular}{|c|c|c|c|c|c|c|c|c|c|c|c|c|c|c|c|c|c|c|c|c|c|c|c|c|c|c|c|}
\hline $\mathrm{c}^{\prime} / \mathrm{c}^{\prime \prime}$ & \multicolumn{27}{|c|}{ Chromosomes } \\
\hline $1^{\prime}$ & 1 & 0 & 0 & 0 & 0 & 0 & 0 & 1 & 0 & 1 & 1 & 1 & 0 & 11 & 0 & 1 & 11 & 0 & \begin{tabular}{|l|}
0 \\
\end{tabular} & 11 & 1 & 1 & 0 & 1 & 0 & 0 & 1 \\
\hline $2^{\prime \prime}$ & 0 & 0 & 1 & 0 & 1 & 0 & 1 & 1 & 0 & 0 & 1 & 0 & 1 & 1 & 1 & 1 & 1 & 0 & 0 & 0 & 0 & 1 & 0 & 1 & 1 & 1 & 1 \\
\hline $3^{\prime}$ & 1 & 1 & 0 & 1 & 0 & 1 & 1 & 1 & 0 & 1 & 1 & 0 & 0 & \begin{tabular}{|l|}
1 \\
\end{tabular} & 0 & 0 & 1 & 1 & 1 & \begin{tabular}{|l|l|}
0 \\
\end{tabular} & 1 & 1 & 1 & 1 & 0 & 0 & 1 \\
\hline $4^{\prime}$ & 1 & 1 & 1 & 1 & 1 & 0 & 1 & 1 & 1 & 0 & 1 & 1 & 1 & 1 & 1 & 1 & 0 & 0 & 1 & 1 & 0 & 0 & 1 & 0 & 0 & 1 & 1 \\
\hline $5^{\prime \prime}$ & 1 & 1 & 1 & 0 & 1 & 1 & 0 & 0 & 0 & 0 & 0 & 1 & 0 & 1 & 1 & 1 & 1 & 1 & 0 & 0 & 1 & 0 & 1 & 0 & 1 & 1 & 0 \\
\hline $6^{\prime}$ & 1 & 1 & 0 & 0 & 0 & 0 & 1 & 0 & 1 & \begin{tabular}{|l|}
0 \\
\end{tabular} & 0 & 1 & 0 & \begin{tabular}{|l|}
1 \\
\end{tabular} & 1 & 1 & 1 & 1 & 1 & \begin{tabular}{|l|}
0 \\
\end{tabular} & 1 & 1 & 0 & 1 & \begin{tabular}{|l|}
1 \\
\end{tabular} & 1 & 0 \\
\hline $7^{\prime}$ & U & 1 & 1 & 1 & 0 & 0 & 1 & 0 & 0 & 0 & 0 & \begin{tabular}{l|l}
0 \\
\end{tabular} & 1 & \begin{tabular}{|l|l|}
1 \\
\end{tabular} & 1 & 0 & \begin{tabular}{|l|}
0 \\
\end{tabular} & 1 & 1 & \begin{tabular}{|l|}
1 \\
\end{tabular} & 0 & \begin{tabular}{|l|}
0 \\
\end{tabular} & 1 & 0 & \begin{tabular}{|l|l|}
0 \\
\end{tabular} & \begin{tabular}{|l|}
0 \\
\end{tabular} & 0 \\
\hline $8^{\prime \prime}$ & 1 & 1 & 0 & 1 & 0 & 1 & 0 & 1 & 0 & 1 & 1 & 0 & 1 & \begin{tabular}{|l|}
1 \\
\end{tabular} & 1 & 0 & 1 & 0 & 1 & \begin{tabular}{|l|}
0 \\
\end{tabular} & 0 & \begin{tabular}{|l|}
1 \\
\end{tabular} & 1 & 0 & 0 & 0 & 0 \\
\hline $9^{\prime}$ & 1 & 1 & 1 & 1 & 0 & 1 & 0 & 0 & 1 & 1 & 0 & 1 & 1 & \begin{tabular}{|l|}
1 \\
\end{tabular} & 0 & 0 & \begin{tabular}{|l|}
0 \\
\end{tabular} & 1 & \begin{tabular}{|l|}
0 \\
\end{tabular} & \begin{tabular}{|l|}
0 \\
\end{tabular} & 0 & \begin{tabular}{|l|}
0 \\
\end{tabular} & 0 & 1 & 1 & \begin{tabular}{|l|}
0 \\
\end{tabular} & 0 \\
\hline $10^{\prime}$ & 7 & 1 & 1 & 0 & 1 & 1 & 1 & 0 & 0 & 0 & 0 & 1 & 0 & \begin{tabular}{|l|}
0 \\
\end{tabular} & 1 & 0 & 1 & 0 & 1 & \begin{tabular}{|l|}
1 \\
\end{tabular} & 0 & 1 & 1 & 0 & 11 & 1 & 0 \\
\hline $11^{\prime \prime}$ & 0 & 1 & 1 & 0 & 1 & 1 & 0 & 1 & 0 & 1 & 0 & 0 & 0 & \begin{tabular}{|l|l|}
0 \\
\end{tabular} & 1 & 1 & \begin{tabular}{|l|}
0 \\
\end{tabular} & 0 & 1 & \begin{tabular}{|l|}
1 \\
\end{tabular} & 0 & \begin{tabular}{|l|}
1 \\
\end{tabular} & 1 & 0 & \begin{tabular}{|l|}
1 \\
\end{tabular} & \begin{tabular}{|l|}
1 \\
\end{tabular} & 0 \\
\hline $12^{\prime}$ & 0 & 1 & 0 & 1 & 1 & 0 & 0 & 1 & 1 & \begin{tabular}{|l|}
1 \\
\end{tabular} & 0 & 1 & 1 & \begin{tabular}{|l|}
1 \\
\end{tabular} & 1 & 0 & \begin{tabular}{|l|}
0 \\
\end{tabular} & 0 & 1 & \begin{tabular}{|l|}
1 \\
\end{tabular} & 0 & \begin{tabular}{|l|}
0 \\
\end{tabular} & 1 & 0 & 1 & \begin{tabular}{|l|}
0 \\
\end{tabular} & 1 \\
\hline
\end{tabular}

Table 18. Chromosomes after cross over and before mutation

\begin{tabular}{|c|c|c|c|c|c|c|c|c|c|c|c|c|c|c|c|c|c|c|c|c|c|c|c|c|c|c|c|}
\hline$c^{\prime \prime \prime}$ & \multicolumn{27}{|c|}{ Chromosomes } \\
\hline $1^{\prime \prime \prime}$ & 1 & \begin{tabular}{|l|}
0 \\
\end{tabular} & 0 & 0 & U & 0 & 0 & 1 & 0 & 1 & 1 & 1 & 0 & 1 & 0 & 1 & 1 & & 0 & 1 & 1 & 1 & \begin{tabular}{l|l}
0 \\
\end{tabular} & 11 & \begin{tabular}{|l|}
0 \\
\end{tabular} & 0 & 1 \\
\hline $2^{\prime \prime \prime}$ & 0 & 0 & 1 & 0 & & 0 & 1 & 7 & & 0 & 0 & 0 & 1 & & & & & & 0 & 0 & 0 & 1 & 0 & 1 & 1 & 1 & 1 \\
\hline $3^{\prime \prime \prime}$ & 1 & 1 & 0 & 1 & 0 & 1 & 1 & 1 & ( & 1 & 1 & 0 & 0 & 1 & & & & & 1 & 0 & 0 & 1 & 1 & 1 & \begin{tabular}{|l|}
0 \\
\end{tabular} & 0 & 1 \\
\hline $4^{\prime \prime \prime}$ & 1 & 1 & 1 & 1 & 1 & 1 & 1 & 1 & & 0 & 1 & 1 & & & & & & & 1 & 1 & 0 & 0 & 1 & 0 & \begin{tabular}{|l|}
0 \\
\end{tabular} & 1 & 1 \\
\hline $5^{\prime \prime \prime}$ & 1 & 1 & 1 & 1 & 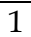 & 1 & 0 & 0 & l & 0 & U & 1 & & & & & & & 0 & 0 & 1 & 1 & 1 & 0 & 1 & 1 & 0 \\
\hline $6^{\prime \prime \prime}$ & 1 & 1 & 0 & 0 & 0 & 0 & 1 & 0 & 1 & 0 & 0 & 1 & 0 & & & & & & 1 & 0 & 1 & 1 & 0 & 1 & 1 & 1 & 0 \\
\hline $7^{\prime \prime \prime}$ & 0 & 1 & 1 & 1 & & 0 & & 0 & & 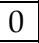 & 0 & 0 & & & & & & & 1 & 1 & 0 & 1 & 0 & 0 & \begin{tabular}{|l|}
0 \\
\end{tabular} & 0 & 0 \\
\hline $8^{\prime \prime \prime}$ & 1 & 1 & 0 & 1 & 0 & 1 & 0 & 1 & 0 & 1 & 1 & 0 & 1 & 1 & 1 & U & & U & 1 & 0 & 0 & 1 & 1 & 0 & 0 & 0 & 0 \\
\hline $9^{\prime \prime \prime}$ & 1 & 1 & 4 & 7 & & 1 & 1 & 0 & 1 & 2 & 0 & 1 & & & & & & & 0 & 0 & 0 & 0 & 0 & 1 & 1 & 0 & U \\
\hline $10^{\prime \prime \prime}$ & 1 & 1 & 1 & 0 & & 1 & 1 & 0 & 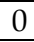 & 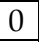 & 0 & 1 & & & & & & & 1 & 0 & 0 & 1 & 1 & 0 & 1 & 1 & 0 \\
\hline $11^{\prime \prime}$ & 0 & 1 & 1 & 0 & & 1 & 0 & 0 & & 1 & 0 & 0 & 0 & & 1 & & & & 1 & 1 & 0 & 1 & 1 & \begin{tabular}{|l|}
0 \\
\end{tabular} & 1 & 1 & \begin{tabular}{|l|l|}
0 \\
\end{tabular} \\
\hline $2^{\prime \prime}$ & 0 & 4 & 0 & & 1 & 0 & 0 & 1 & 1 & 1 & 0 & 1 & 1 & & 1 & & & & 1 & 1 & 0 & 0 & & 0 & & 0 & \\
\hline
\end{tabular}

* Mutated genes are shown as bold

Table 19. New Population (Population of chromosome after mutation) 


\begin{tabular}{|c|c|c|c|c|c|c|c|c|c|c|}
\hline \multirow{3}{*}{\multicolumn{2}{|c|}{$\begin{array}{c}\text { Operating } \\
\text { Parameters }\end{array}$}} & \multicolumn{9}{|c|}{ Buyer ' $j$ ' } \\
\hline & & \multicolumn{3}{|c|}{1} & \multicolumn{3}{|c|}{2} & \multicolumn{3}{|c|}{3} \\
\hline & & $x_{i j o p t}$ & $O x_{i j o p t}$ & $W_{i j o p t}$ & $x_{\text {ijopt }}$ & $O x_{i j o p t}$ & $W_{\text {ijopt }}$ & $x_{i j o p t}$ & $O x_{i j o p t}$ & $W_{i j o p t}$ \\
\hline \multirow{2}{*}{ Supplier ' $i$ ' } & 1 & 1363 & 0 & 20.66 & 1637 & 0 & 19.38 & 0 & 0 & 0 \\
\hline & 2 & 0 & 0 & 0 & 1362 & 0 & 20.14 & 1638 & 276 & 19.32 \\
\hline \multicolumn{2}{|c|}{ Sales quantity } & \multicolumn{3}{|c|}{1363} & \multicolumn{3}{|c|}{2999} & \multicolumn{3}{|c|}{1914} \\
\hline \multicolumn{2}{|c|}{ Sales price } & \multicolumn{3}{|c|}{22.86} & \multicolumn{3}{|c|}{21.4} & \multicolumn{3}{|c|}{20.42} \\
\hline \multicolumn{2}{|c|}{ Channel profit } & \multicolumn{9}{|c|}{22724.52} \\
\hline
\end{tabular}

Table 20. Optimal operating parameters

\section{Concluding remarks}

\subsection{Summary}

This section reports the robustness of the model and methodology, limitation, in the current research, managerial implications and potential scope for future research. This chapter addressed to the soft issues of profit sharing and pricing in SCM and has concentrated on development of decision support heuristics to determine the optimal or near optimal operational parameters (Sales quantities, Prices (sales and contract) and outsourcing quantities and transaction quantities) for maximum channel profit to the two-echelon SC models operating under VMI mode.

i. $\quad$ Single Vendor Single Buyer (SV_SB)

ii. Single Vendor Multiple Buyer's (SV_MB)

iii. Multiple Vendors Multiple Buyers (MV_MB)

iv. Single Vendor Multiple Buyer's with Outsourcing (SV_MBO)

v. Multiple Vendors Multiple Buyers with Outsourcing (MV_MBO)

Furthermore, this chapter illustrated application of VMI systems for two-echelon SC models in the agricultural sector. Fixation of contract price for the different revenue ratio is a tedious process, which leads to conflicts between partners, if it is not properly adopted in VMI system. To overcome the above limitation, a new methodology is required to determine the contract prices for known revenue shares between vendor and buyer. Hence, this chapter proposes an iterative heuristic procedure for SV_SB model to find optimal or near optimal operational parameters. The mathematical formulation of the remaining four models (SV_MB, MV_MB, SV_MBO, MV_MBO) belongs to Nonlinear Integer Programming (NIP) and Mixed Integer Nonlinear Programming (MINP) problems. The Hessian matrix of the objective functions confirms the nature of it as non-convex. Hence GA and SAA based heuristics are proposed to solve the above models.

Iterative heuristic procedure provides optimal/near optimal solution when compared with the methodology proposed by Dong \& Xu (2002) for the same SV_SB operating in VMI mode of operation, but under equal revenue share cases. GA and SAA based heuristics provides near optimal solution when compared with i) LINGO optimization solver for smaller size problems ii) DX methodology of Dong \& Xu (2002) by reducing the models (2-5) into SV_SB. The computational time increases with increase in number of vendors and buyers. However the problem is static and justifiable.

The robustness of the models are evaluated by changing the influencing parameters such as limits on sales quantity, slope of demand function, cost of holding and cost of setup/order. Variation in holding and order setup cost has less impact in sales quantities, sales price and 
contract price, whereas it has more impact on the channel profit. Variations in limits on sales quantity and slope of demand pattern have more impact on operational parameters and channel profit. Hence it is concluded that the model presented, the heuristics proposed and the analysis carried out in this chapter work would aid SC managers to take appropriate decision in two- echelon VMI systems.

\subsection{Future directions}

- Inventory holding cost and order setup cost for vendor in all the above models are assumed as sum of both holding cost and order setup cost, but in practice the inventory cost will be less. Therefore the vendor profit and channel profit would be more in real time. Future analysis can consider various combination of inventory holding and order setup cost to the above models and the insight of the problem could be studied.

- The distribution cost in all the models varies parabolically depending upon the increase in quantity and mode of transportation. Since in VMI, the vendor has to monitor inventory and to replenish products as and when required, there will be exponential variation in distribution cost depending upon the increase in quantity and mode of transportation. Hence future research can represent distribution cost with respect to product and incorporate fixed transportation cost to depict the real cost of transportation.

- $\quad$ All the above models assume reverse linear relationship between price-sales quantities. The impact on optimal operational parameters for various demand curves can be studied for other categories of product.

- The mode of operation assumes zero lead time and would not allow backlog and stock out. Researchers in future can accommodate these factors along with shortage cost for varying service levels while developing two-echelon models.

- Concept of heuristics proposed for two-echelon models could be extended for multi echelon models

- This chapter illustrated the development of heuristics for sectors like agriculture, but this can be extended to any kind of product and service sectors such as milk, engineering services etc.

- Development of knowledge managed systems for two-echelon VMI systems to determine operational parameters for maximum channel profit based on the experts experience and with the data available from the market.

- The other soft issues such as organizational resistance to change, inter-functional conflicts, team oriented performance measures and channel power shift have not been considered while modelling two-echelon SC. Hence future researchers may pay more attention to these issues.

\section{Acknowledgement}

The authors thank the Management, the Principal, and the Head of Mechanical Engineering Department of Thiagarajar College of Engineering, Madurai, India and the Nottingham University Business School, Nottingham, UK for providing necessary facilities to carry out this work. The authors specially thank Department of Science and Technology (SERC Division), New Delhi for the BOYSCAST fellowship (SR/BY/E-09/06) to carry out this research work at Nottingham University and All India Council for Technical Education 
(F.No. 1-51/FD/CA/(16) 2006-07 dated 12/12/2006) for the career award for the young teachers offered to the first author.

\section{References}

Achabal, D.D., Mcintyre, S.H., Smith \& S.A., Kalyanam, K. (2000). A Decision support system for VMI. Journal of Retailing, 76(4), 430 -54.

Banerjee A. (1986). A joint economic lot size model for purchaser and vendor. Decision Science, 17, 292-311.

Ballou, R. H., Gilbert, S. M. \& Mukherjee, A. (2000). New managerial challenges from supply chain opportunities. Industrial Marketing Management, 29, 7-18.

Bhattacharjee, S \& Ramesh, R. (2000). A multi-period profit maximizing model for retail supply chain management: An integration of demand and supply side mechanism. European Journal of Operational Research, 122, 584-601.

Burke, M. (1996). Its Time for Vendor Managed Inventory. Industrial Distribution. 85-90.

Cachon, G.P., (2001). Stock wars: Inventory competition in a two-echelon supply chain with multiple retailers. Operations Research, 49(5), 658-74.

Cachon, G.P \& Zipkin, P.H. (1999). Competitive and cooperative Inventory Policies in a two stage supply chain. Management science, 45(7), 936-953.

Casati, F., Dayal, U \& Shan. M-C. (2001). E Business Applications for Supply Chain Management: Challenges and Solutions. IEEE Journal, 1063-6382 / 01, 71-78.

Cetinkaya, S. \& Lee C. Y. (2000). Stock Replenishment and Shipment Scheduling For Vendor-Managed Inventory Systems. Management Science, 46(2), 217-232.

Chopra, S. (2003). Designing the Distribution Networks in a supply Chain. Transportation Research-Part E, 39, 123-140.

Clark, T.H. \& Croson, D.C. (1994). H.E. Butt Grocery Company: a leader in ECR implementation. Harvard Business School Case, 9, 195-125.

Corne D., Dorigo M. \& Glover F. (1999). New Ideas in Optimisation. McGraw-Hill.

Costa, L. \& Oliveira, P. (2001). Evolutionary algorithms approach to the solution of mixed integer nonlinear programming problems. Computers and Chemical Engineering, 25, 257-66.

Desarbo, W.S., Rao, V.R., Steckel, J.H., Wind, J. \& Colombo, R., (1987). A Friction model for describing and forecasting price changes. Journal of Marketing Science, 6 (4), 299-319.

Disney, S.M. \& Towill, D.R. (2003). Vendor managed inventory and bull whip reduction in a two level supply chain. International Journal of Operations and Production Management. 23(6), 625-651.

Disney, S.M. \& Towill, D. R. (2002). A procedure for optimization of the dynamic response of a Vendor Managed Inventory system. Computers and Industrial Engineering, 43, 27-58.

Dong, Y. \& Xu, K. (2002). A supply chain model of vendor managed inventory. Transportation Research Part E: Logistics and Transportation Review, 38(2), 75-95.

Eglese, R.W., (1990). Simulated Annealing: A tool for Operational Research. European Journal of Operational Research, 271-281.

Fry, M.J. (2002). Collaborative and cooperative agreement in the supply chain, Ph.D. Thesis report, University of Michigan.

Gallego, G. \& Vanryzin, G. (1994). Optimal Dynamic Pricing of Inventories with Stochastic demand Over Finite Horizons. Management Science, 40, 999-1020. 
Ganeshan,R. (1999). Managing supply chain inventories: A multiple retailer, one warehouse, multiple supplier model. International Journal of Production Economics, 59, 341-54.

Gavirneni, S., (2001). Benefits of cooperation in a production distribution environment. European Journal of Operational Research, 130(3), 612 - 22.

Giannoccaro, I. \& Pontrandolfo, P. (2004). Supply Chain Coordination by revenue sharing contracts. International Journal of Production Economics, 89, 131-139.

Gjerdrum , J., Shah, N. \& Papageorgiou, L.G. (2002). Fair Transfer Price and Inventory holding policies in Two Enterprise Supply Chains. European Journal of Operational Research, 143, 582 - 599.

Glover, F \& Gkochenberger, G (2001). (eds.) Handbook in Meta heuristics. Kluwer Academic Publishers.

Grieger, M. (2003). Electronic marketplaces: A literature review and a Call for Supply chain management research. European Journal of Operational Research, 144, 280-294.

Goyal, S. K., 1997. An integrated inventory model for a single supplier-single customer problem. International Journal of Production Research, 15, 107-111.

Goyal, S.K. \& Nebebe,F. (2000). Determination of economic production- shipment policy for a single-vendor-single-buyer system. European Journal of Operational Research 121, 175-178.

Hammond, J.H, (1990). Quick response in the apparel industry. Harvard Business School Note N9-690-038, Cambridge, MA.

Hill, R.M. (1997). The single-vendor single-buyer integrated production-inventory model with a generalised policy. European Journal of Operational Research, 97, 493-499.

Hoque, M.A \& Goyal, S.K, (2000). An optimal policy for a single-vendor single-buyer integrated production-inventory system with capacity constraint of the transport equipment. International Journal of Production Economics 65, 305-315.

Kirkpatrick, S., Gelatt, C.D. \& Vecchi, M.P. (1983). Optimization by simulated annealing. Science 220, 671-679.

Klastorin, T. (2004). New Product Introduction: Timing, Design, and Pricing. Manufacturing and Service Operations Management 6(4), 302-320.

Lau, A.H.L. \& Lau. H-S. (2003). Effects of a demand curve's shape on the optimal solutions of a multi echelon inventory / pricing model. European Journal of Operations Research $147,530-548$.

Latamore \& Benton,G., 1999. The farm business unit customers; Customers, Suppliers Drawing Closer through VMI. APICS: The Performance Advantage, 12(7), 22-25.

Lee, C.C \& Chu, W.H.J., 2005. Who should control inventory in a supply chain. European Journal of Operational Research, 164(1), 158-72.

Lourenco, H.R. (2005). Logistics Management: an opportunity for Metaheuristics, in Metaheuristics Optimization via Memory and Evolution. C. Rego and B. Alidaee (eds.), Kluwer Academic Publishers, 329-356.

Lu, L. (1995). A one-vendor multi-buyer integrated inventory model. European Journal of Operational Research, 81(2), 312-23.

Mabert, V. A. \& Venkataramanan, M.A. (1998). Special Research Focus on Supply Chain Linkages: Challenges for Design and Management in the 21st Century, Decision Sciences, 29(3), 537-552.

Mccall, J., (2005). Genetic algorithms for modelling and optimisation. Journal of Computational and Applied Mathematics, 184(1), 205-222. 
Maloni, M.J \& Benton, W.C. (1997). Supply Chain Partnership: Opportunities for Operations Research. European Journal of Operational Research 101, 419-429.

Masters, T. (1993). Practical Neural Network Recipes in C++. NewYork, Academic Press.

Michalewicz, Z. (1994). Genetic Algorithms + Data Structures $=$ Evolution Programs. $2^{\text {nd }}$ Edition, Springer, Berlin.

Min, H. \& Zhou, G. (2002). Supply chain modelling: past, present and future. Computers and Industrial Engineering 43,231-249.

Minner, S., (2003). Multiple-supplier inventory models in supply chain management: A review. International Journal of Production Economics 81-82, 265-79.

Mishra, B.K., \& Raghunathan, S. (2004). Retailer vs. Vendor Managed Inventory and Brand Competition. Management Science 50(4), 445-457.

Nachiappan, SP., Jawahar, N. \& Ganesh, M., (2006). Pricing in Vendor Managed Inventory Systems. International Journal of Logistics Systems and Management, 2(1), 19- 40.

Nachiappan, SP., Gunasekaran, A., \& Jawahar, N. (2007). Knowledge management system for operating parameters in two-echelon VMI supply chains. International Journal of Production Research 45(11), 2479-2505.

Nachiappan, SP.\& Jawahar, N. (2007). A genetic algorithm for optimal operating parameters of VMI system in a two-echelon supply chain. European Journal of Operational Research 183(3), 1433-1452.

Nachiappan, SP., Jawahar, N. \& Arunkumar, A.C (2007a). Evolution of operating parameters for a Multiple Vendors and Multiple Buyers Vendor Managed Inventory System with outsourcing using Simulated Annealing Algorithm. International Journal of Industrial Management and Optimization, 3(3), 597-618.

Parks, L. \& Popolillo, M.C (1999). Co-Managed Inventory is focus of Vendor/ Retailer Pilot. Drug Store News, 27, 71.

Polatoglu, L.H. (1991). Optimal order quantity and pricing decisions in single period inventory systems. International Journal of Production Economics, 23, 175-185.

Ponnambalam, S.G., Jawahar, N. \& Aravindan, P. (1999). A simulated annealing algorithm for job shop scheduling. Production planning and control, 10, 767-777.

Ravindran, A., Phillips, D.T. \& Solberg, J.J., (2000). Operations Research: Principles and Practice. $2^{\text {nd }}$ edition; New York: John Wiley \& Sons.

Rajan, A., Rakesh, A \& Steinberg, R. (1992). Dynamic pricing and ordering decisions by a monopolist. Management Science 38, 240-262.

Rutenbar, R.A. (1989). Simulated annealing algorithms: An overview. IEEE Circuits and Devices Magazine, 19-26.

Sedarage, D., Fujiwara, O \& Luong, H.T., (1999). Determining optimal order splitting and reorder level for $\mathrm{N}$-supplier inventory systems. European Journal of Operational Research, 116, 389-404.

Simchi-Levi D., Kaminsky, P. \& Simchi-Levi, E. (2000). Designing and Managing the Supply Chain, McGraw-Hill.

Shapiro, J. F., (2001). Modeling the supply chain, Pacific Grove, CA: Wadsworth Group

Tronstad, R. (1995). Pricing. Journal of Market Analysis and Pricing, 39 -45.

Viswanathan, S. (1998). Optimal strategy for the integrated vendor-buyer inventory model. European Journal of Operational Research 105(1), 38-42.

Waller, M., Johnson, M.E.\& Davis, T. (2001). Vendor managed inventory in the retail supply chain. Journal of Business Logistics 20(1), 183-203. 
Williams, M.K. (2000). Making Consignment and Vendor Managed Inventory work for you. Hospital Material Management Quarterly, 21(4), 59-63.

Yao, M.J \& Chiou,C.C.(2004). On a replenishment coordination model in an integrated supply chain with one vendor and multiple buyers. European Journal of Operational Research 159, 406-419.

Yokota,T., Gen, M. \& Li. Y.X. (1996). Genetic Algorithm for non linear mixed integer programming problems and its applications. Computers and Industrial Engineering 30(4), $905-17$.

\section{Nomenclature}

$\begin{array}{ll}\text { a } & \text { Constant. } \\ a_{j} & \text { Intercept value for the demand pattern of the } j^{\text {th }} \text { buyer } \\ b & \text { Slope of Demand pattern - Selling Price Curve. } \\ b_{j} & \text { Cost Slope of the demand pattern of the } j^{\text {th }} \text { buyer } \\ c_{,} c^{\prime}, c^{\prime \prime}, c^{\prime \prime \prime} & \text { Chromosome } \\ C & \text { Capacity of the vendor } \\ C_{i} & \text { Capacity of the vendor ' } i \text { ' } \\ c p(c) & \text { Cumulative probability of survival } \\ c p(c-1) & \text { Cumulative probability of survival of previous chromosome } \\ E O Q & \text { Economic order quantity } \\ E O Q_{j} & \text { Economic order quantity of } j^{\text {th }} \text { buyer } \\ E O Q_{i j} & \text { Economic order quantity from } i^{\text {th }} \text { vendor to } j^{\text {th }} \text { buyer } \\ F & \text { Frame work } \\ f i t(c) & \text { Fitness function } \\ H_{b} & \text { Holding cost per unit per unit time of the buyer in independent mode of } \\ H_{b j} & \text { operation. } \\ H_{S} & \text { Holding cost of the } j^{\text {th }} \text { buyer in independent mode } \\ H_{S i} & \text { Holding cost per unit per unit time of the vendor in independent mode of } \\ H_{V M I} & \text { operation. } \\ H_{j V M I} & \text { Holding cost of the vendor ' } i \text { ' in independent mode } \\ H_{i j V M I} & \text { Inventory cost of vendor per unit per unit time in VMI mode of operation. } \\ i & \text { Holding cost of the vendor in VMI mode } \\ j & \text { Holding cost of the vendor ' } i \text { ' to } j^{\text {th }} \text { buyer in VMI mode } \\ n e w f i t(c) & \text { Vendor identifier }(i=1 \text { to } m \text { ) } \\ O S M & \text { Number of vendors }\end{array}$




\begin{tabular}{|c|c|}
\hline$O S M_{j}$ & Order and stock maintenance cost to the vendor for each buyer \\
\hline$O S M_{i j}$ & Order and stock maintenance cost to the vendor ' $i$ ' for each buyer ' $j$ ' \\
\hline$O x$ & Outsourcing transaction quantity \\
\hline$O x_{i j}$ & Outsourcing transaction quantities between vendor ' $i$ ' and buyer ' $j$ ' \\
\hline$O x_{i j m i n}$ & $\begin{array}{l}\text { Minimum outsourcing transaction quantities between vendor ' } i \text { ' and buyer } \\
\text { ' } j \text { ' }\end{array}$ \\
\hline$O x_{i j m a x}$ & $\begin{array}{l}\text { Maximum outsourcing transaction quantities between vendor ' } i \text { ' and } \\
\text { buyer ' } j \text { ' }\end{array}$ \\
\hline$O x_{i j o p t}$ & $\begin{array}{l}\text { Optimal outsourcing transaction quantities between vendor ' } \mathrm{i} \text { ' and buyer } \\
\text { ' } \mathrm{j} \text { ' }\end{array}$ \\
\hline$O C x_{i j}$ & Outsourcing cost from $\mathrm{i}^{\text {th }}$ vendor to $\mathrm{j}^{\text {th }}$ buyer \\
\hline$o_{y}$ & Outsourcing quantity \\
\hline$o_{\text {yopt }}$ & Optimal outsourcing quantities \\
\hline$o_{c}$ & Outsourcing cost of the vendor \\
\hline$o_{c j}$ & Outsourcing cost of the vendor to $j^{\text {th }}$ buyer $\left(\mathrm{o}_{\mathrm{cj}}=\mathrm{O}_{\mathrm{c}} / \mathrm{n}\right)$ \\
\hline p_cross & Probability of the cross over \\
\hline$P$ & Pricing \\
\hline$P_{b}$ & Buyer Profit under Independent mode of operation \\
\hline$P_{b}{ }^{\prime}$ & Buyer Profit in VMI mode \\
\hline$P_{b j}$ & Profit of $j^{\text {th }}$ buyer in VMI mode \\
\hline$P_{c}$ & Channel profit in independent mode \\
\hline$P_{c^{\prime}}$ & Channel profit in VMI mode \\
\hline$P_{c}^{\prime \prime}$ & Channel profit obtained after perturbation in Simulated annealing \\
\hline$\Delta P_{c}$ & Difference in Channel Profit \\
\hline$P_{\text {copt }}$ & Optimal channel profit in VMI mode \\
\hline$P_{s}$ & Vendor Profit under Independent mode of operation. \\
\hline$P_{s}^{\prime}$ & Vendor Profit in VMI mode \\
\hline$P_{s i}$ & Profit of vendor ' $i$ ' in VMI mode \\
\hline$P_{s j}$ & $\begin{array}{l}\text { Profit obtained by vendor when supplying products to the buyer ' } j \text { ' in VMI } \\
\text { mode }\end{array}$ \\
\hline$P_{s i j}$ & Profit obtained by vendor ' $i$ ' when supplying products to the buyer ' $j$ ' \\
\hline$P D$ & Production distribution cost of the buyer. \\
\hline$P D_{j}$ & Production distribution cost of the $j^{\text {th }}$ buyer. \\
\hline$P D_{i j}$ & Production distribution cost from $i^{\text {th }}$ vendor to the $j^{\text {th }}$ buyer. \\
\hline$p(c)$ & Probability of survival of chromosome ' $\mathrm{c}$ ' \\
\hline p_mut & Probability of mutation \\
\hline pop_size & Population size \\
\hline$P(y)$ & Sales Price \\
\hline
\end{tabular}




\begin{tabular}{|c|c|}
\hline$P\left(y_{j}\right)$ & Sales price of the $j^{\text {th }}$ buyer corresponding to sales quantity ' $y_{j}$ ' \\
\hline$P\left(y_{\text {opt }}\right)$ & Sales price at optimal sales quantity $y_{\text {opt. }}$ \\
\hline$P\left(y_{\text {jopt }}\right)$ & Optimal sales price of the $j^{\text {th }}$ buyer \\
\hline$P R_{n o n-V M I}$ & $\begin{array}{l}\text { Revenue share ratio between vendor and buyer when they operate under } \\
\text { non-VMI mode }\left(\mathrm{P}_{\mathrm{s}} / \mathrm{P}_{\mathrm{b}}\right) \text {. }\end{array}$ \\
\hline$P R$ & $\begin{array}{l}\text { Revenue share ratio between vendor and buyer when they operate under } \\
\text { VMI mode }\left(\mathrm{P}_{\mathrm{s}}^{\prime} / \mathrm{P}_{\mathrm{b}}^{\prime}\right) \text {. }\end{array}$ \\
\hline$P R_{j}$ & Revenue share ratio between vendor and the $j^{\text {th }}$ buyer \\
\hline$P R_{i j}$ & Revenue share ratio between $i^{\text {th }}$ vendor and the $j^{\text {th }}$ buyer \\
\hline$P_{c}^{\prime}(y)$ & Channel Profit for quantity $y$ in VMI mode of operation. \\
\hline$P_{c}^{\prime}(y-\Delta y)$ & $\begin{array}{l}\text { Channel Profit of VMI mode for the prior incremental value of sales } \\
\text { quantity }\end{array}$ \\
\hline$Q$ & Replenishment quantity \\
\hline$Q_{j}$ & Replenishment quantity to each buyer ' $j$ ' \\
\hline$Q_{i j}$ & Replenishment quantity from vendor ' $i$ ' to buyer ' $j$ ' \\
\hline$r$ & Random number \\
\hline$S_{b}$ & Setup cost per order of the buyer in Independent mode of operation. \\
\hline$S_{b j}$ & Setup cost of the $j^{\text {th }}$ buyer per order in independent mode \\
\hline$S_{S}$ & Setup cost of the vendor per order in independent mode \\
\hline$S_{S i}$ & Setup cost of the vendor ' $i$ ' per order in independent mode \\
\hline $\mathrm{S}_{\mathrm{VMI}}$ & Set up cost per order of the vendor in VMI mode of operation. \\
\hline$S_{j V M I}$ & Setup cost of the vendor per order in VMI mode of operation to buyer ' $j$ ' \\
\hline$S_{i j V M I}$ & Setup cost of the vendor ' $i$ ' per order in VMI mode of operation to buyer ' $j$ ' \\
\hline$T$ & Temperature \\
\hline$t 1, t 2$ & Random numbers generated in Simulated Annealing for perturbation \\
\hline$W$ & Contract price \\
\hline$W_{j}$ & Contract price between vendor and buyer ' $j$ ' \\
\hline$W_{i j}$ & Contract price between vendor ' $i$ ' and buyer ' $j$ ' \\
\hline$W_{\text {opt }}$ & Optimal Contract price. \\
\hline$W_{\text {jopt }}$ & Optimal contract price between vendor and buyer ' $j$ ' \\
\hline$W_{\text {ijopt }}$ & Optimal contract price between vendor ' $i$ ' and buyer ' $j$ ' \\
\hline$x$ & Transaction quantity \\
\hline$x_{i j}$ & Transaction quantities between vendor ' $i$ ' and buyer ' $j$ ' \\
\hline$x_{\text {imin }}$ & Minimum transaction quantities between vendor ' $i$ ' and buyer ' $j$ ' \\
\hline$x_{i j m a x}$ & Maximum transaction quantities between vendor ' $i$ ' and buyer ' $j$ ' \\
\hline$x_{i j o p t}$ & Optimal transaction quantities between vendor ' $i$ ' and buyer ' $j$ ' \\
\hline$y$ & Sales quantity \\
\hline
\end{tabular}




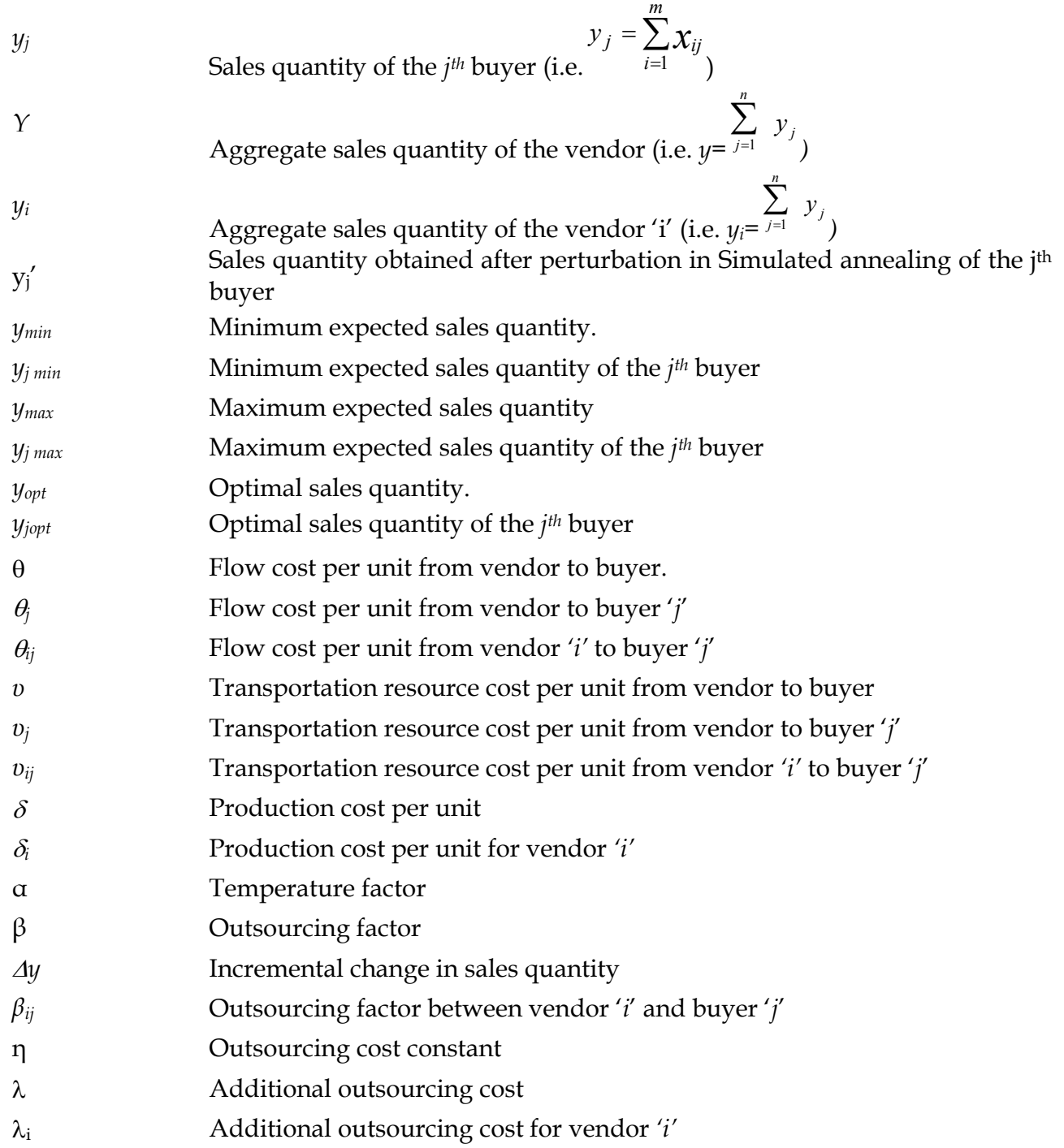




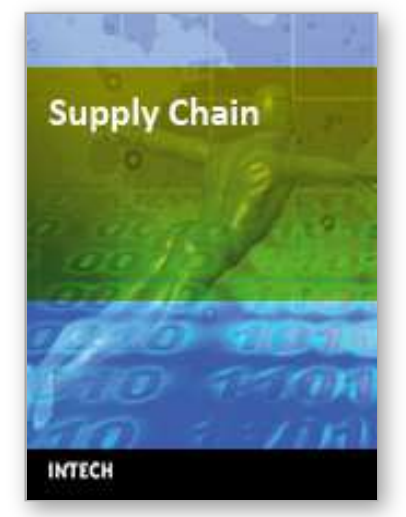

\author{
Supply Chain \\ Edited by Vedran Kordic
}

ISBN 978-3-902613-22-6

Hard cover, 568 pages

Publisher I-Tech Education and Publishing

Published online 01, February, 2008

Published in print edition February, 2008

Traditionally supply chain management has meant factories, assembly lines, warehouses, transportation vehicles, and time sheets. Modern supply chain management is a highly complex, multidimensional problem set with virtually endless number of variables for optimization. An Internet enabled supply chain may have justin-time delivery, precise inventory visibility, and up-to-the-minute distribution-tracking capabilities. Technology advances have enabled supply chains to become strategic weapons that can help avoid disasters, lower costs, and make money. From internal enterprise processes to external business transactions with suppliers, transporters, channels and end-users marks the wide range of challenges researchers have to handle. The aim of this book is at revealing and illustrating this diversity in terms of scientific and theoretical fundamentals, prevailing concepts as well as current practical applications.

\title{
How to reference
}

In order to correctly reference this scholarly work, feel free to copy and paste the following:

Subramanian Nachiappan and Natarajan Jawahar (2008). Pricing in Supply Chain under Vendor Managed Inventory, Supply Chain, Vedran Kordic (Ed.), ISBN: 978-3-902613-22-6, InTech, Available from: http://www.intechopen.com/books/supply_chain/pricing_in_supply_chain_under_vendor_managed_inventory

\section{INTECH}

open science | open minds

\section{InTech Europe}

University Campus STeP Ri

Slavka Krautzeka 83/A

51000 Rijeka, Croatia

Phone: +385 (51) 770447

Fax: +385 (51) 686166

www.intechopen.com

\section{InTech China}

Unit 405, Office Block, Hotel Equatorial Shanghai

No.65, Yan An Road (West), Shanghai, 200040, China

中国上海市延安西路65号上海国际贵都大饭店办公楼405单元

Phone: +86-21-62489820

Fax: +86-21-62489821 
(C) 2008 The Author(s). Licensee IntechOpen. This chapter is distributed under the terms of the Creative Commons Attribution-NonCommercialShareAlike-3.0 License, which permits use, distribution and reproduction for non-commercial purposes, provided the original is properly cited and derivative works building on this content are distributed under the same license. 